دراسة مقارنة لنظم الحوكمة الجامعية في كل من جامعات جنوب

أفريقيا وجامعة هولندا وملى إمكانية الإفادة منها في المملكة العربية

السعودية إمداية

$$
\begin{aligned}
& \text { د.وفاء بنت ابراهيم بن فهل الفريح } \\
& \text { أستاذ مشارك تخصص أصول تربية - كلية التربية - جامعة } \\
& \text { الإمام محمد بن سعود الإسلامية -الملكة العربية السعودية لربية }
\end{aligned}
$$




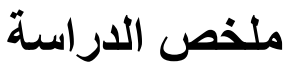

هدفت هذه الدراسة إلى التعرف على الأطر المفاهيمية للحوكمة المؤسسية للجامعات والكثف عن القوى والعوامل المؤثرة في حوكمة الجامعات في دول الدقارنة (هولندا وجنوب أفريقيا) والتعرف على أوجه الثبه الثبه والاختلاف بين خبرات دول الدقارنة في حوكمة الجامعات، والتوصل إلى واقع تطبيق حوكمة الجامعات في

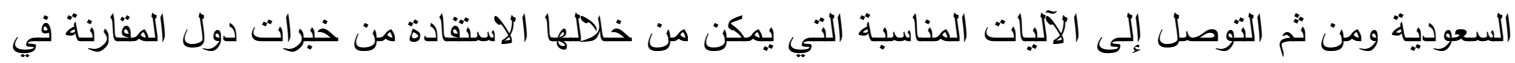

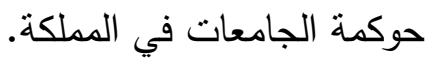

وقد تحددت أوجه المقارنة في كل مما يلي: - أهداف الحوكمة، ومبادئ الحوكمة، وإجراءات الحوكمة ومعايير الحوكمة بين دول المقارنة .

وتوصلت الباحثة من خبرات دول المقارنة في حوكمة الجامعات إلى عدد من المعطيات يمكن تطبيقها في جامعة المملكة من أهمها وضع وثيقة للحوكمة المؤسسية في الجامعات، ومثاركة عملية الحوكمة دئة المؤسسية، وتطوير إدارة الموارد المالية والتوجه نحو اللامركزية في الجامعات. 


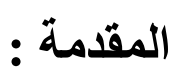

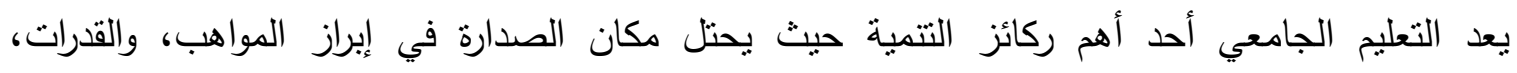

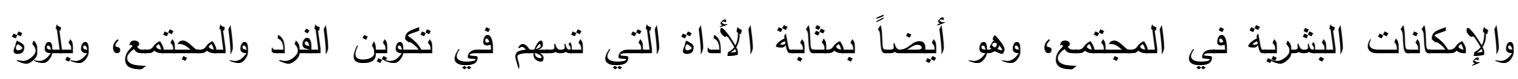
ملامحه في الحاضر والمستقبل معاً.

حيث أدت تدديات القرن الحادي والعشرين وبروز العولمة والثورة المعرفية والتكنولوجية إلى حدوث تغيرات

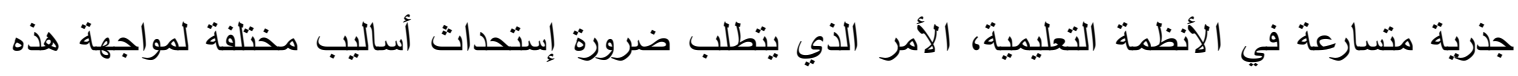

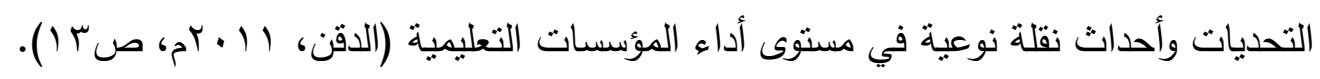

وأدركت كثير من دول العالم أهمية تطبيق الحوكمة الجامعية حيث شهد الاتحاد الأوبي سلسلة من

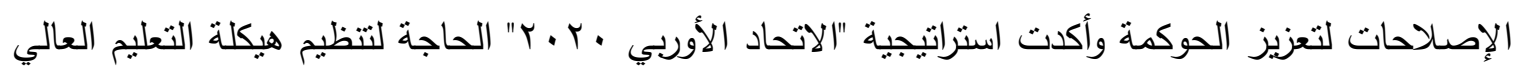

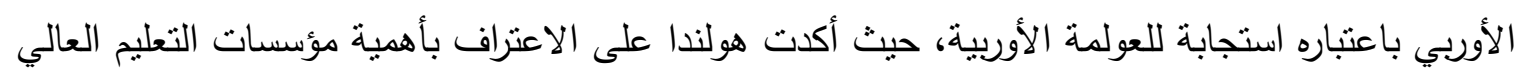

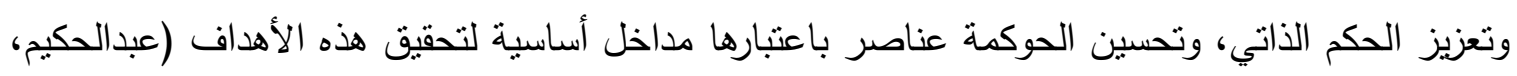

$$
\text { (s.t) }
$$

وعلى مستوى أفريقيا تحتل جنوب أفريقيا المرتبة الأولى بين الدول في البدء في تطبيق نظم الحوكمة

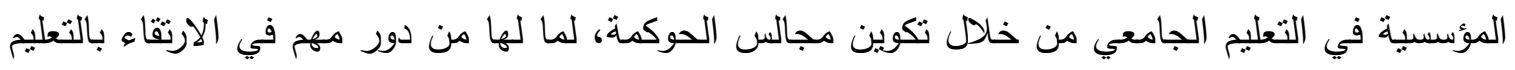

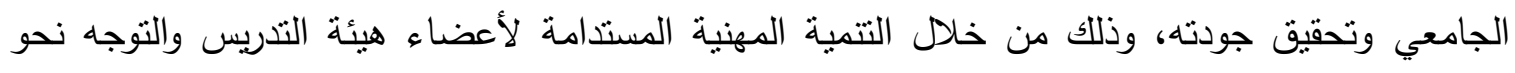

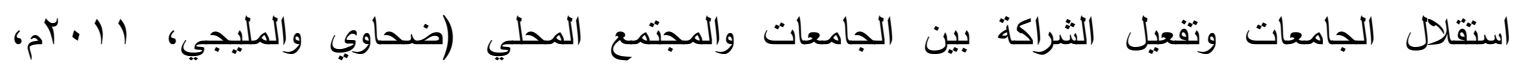
.

وفي ظل تزايد حدة التغيرات والتحديات التي يفرضها مجتمع المعرفة وما يصاحبه من تداعيات مختلفة

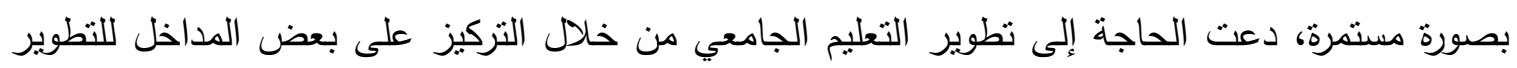

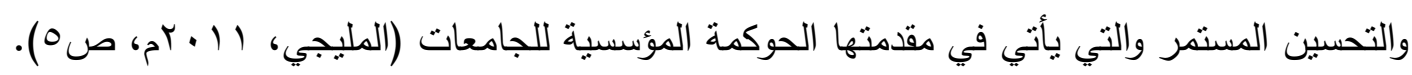
وتعد الحوكمة الجامعية من الداخل الحيثة للإزرتقاء بجودة أداء المنظومة النعليمية كاملة، حيث يهدف

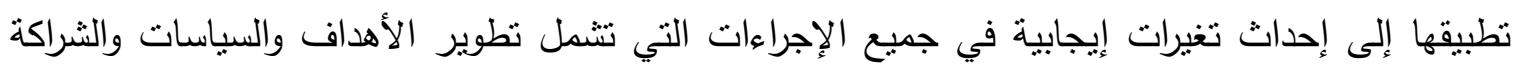

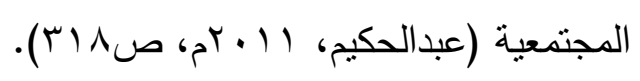




\section{ץ-مشكلة الدراسة:}

لتطوير أداء الجامعات ولإحداث تغيرات إيجابية ولتحقيق ما تطمح إليه المملكة،جاء من بين برامج روئية

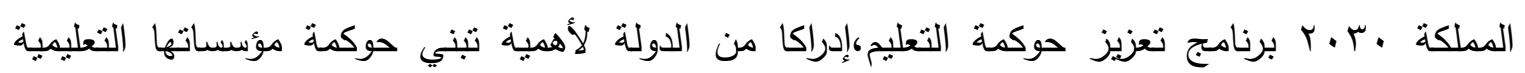
بالثكل الذي يضمن تحقيق الحد المطلوب من مبادئ الحوكمة المرتبطة بالثفافة والمشاركة والمساءلة

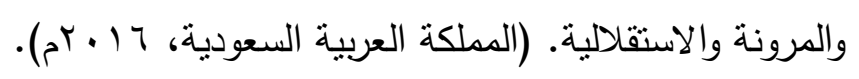

وقد تتاولت العديد من الدراسات المحلية واقع تطبيق الحوكمة في الجامعات السعودية منها دراسة (المفيز ،

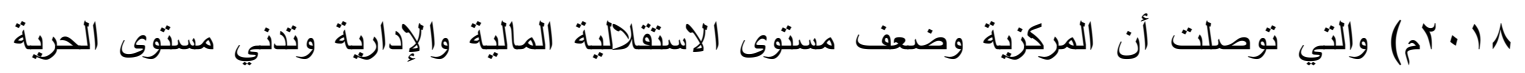

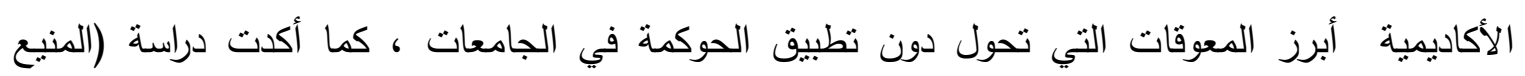

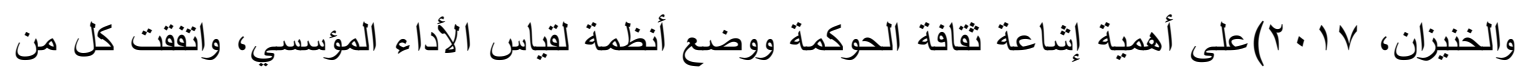

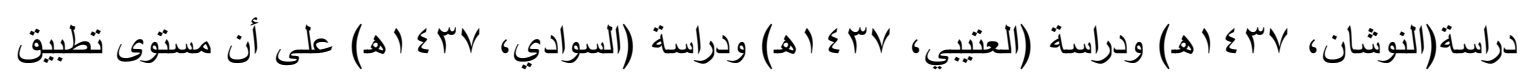

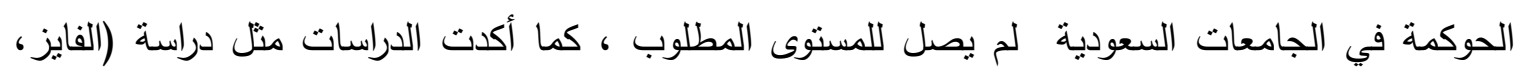

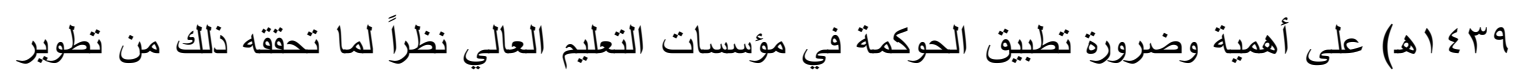

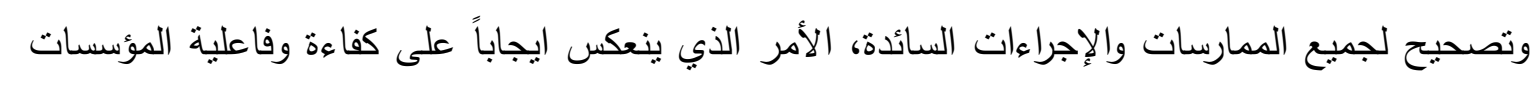
التربوية.

لذا كان من الضروري أن تكرس الجهود والطاقات اللازمة لتحقيق طفرة نوعية في التعليم الجامعي، حيث

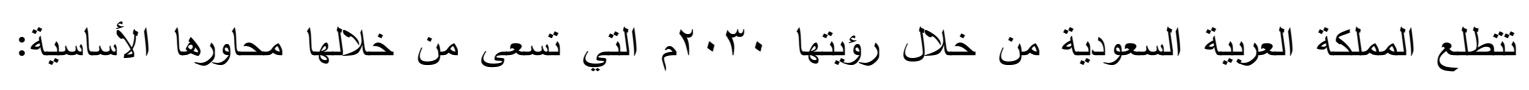

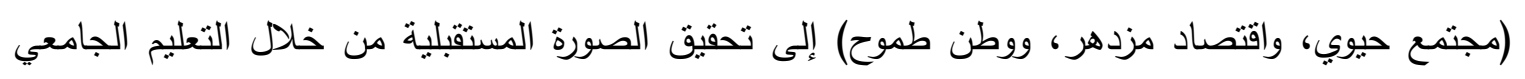

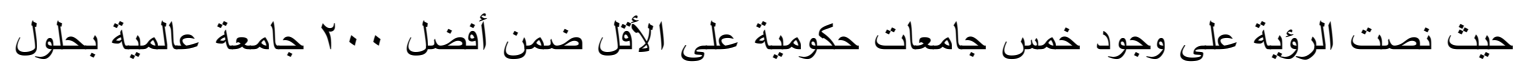

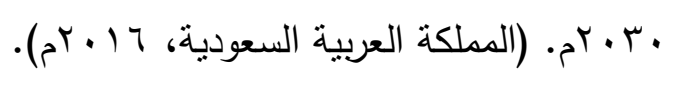

وانطلاقاً لاحتمية إصلاح جوهري لنظام حوكمي في التعليم في الجامعي في المملكة للوصول إلى مستويات

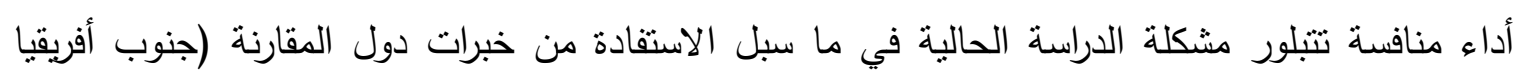
وهولندا) في الحوكمة الجامعية في المملكة العربية السعودية.

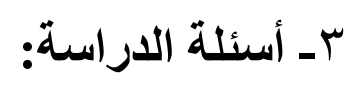

تسعى الدراسه للإجابة على الأسئلة التالية: 
س / ما الأطر النظرية للحوكمة الجامعية في الأدبيات التربوية المعاصرة؟

س r / مانظم حوكمة الجامعات في كل من جامعات جنوب أفريقا وهولندا في ضوء القوى والعوامل الثقافية المؤثرة ؟

س/ / ما أوجه الثبه والاختلاف بين نظم حوكمة الجامعات في كل من جنوب أفريقيا وهولندا ؟ س ـ /ماواقع تطبيق حوكمة الجامعات في المملكة العربية السعودية ؟ سه/ ما أوجه الإفادة من خبرات دول المقارنة (جنوب أفريقيا وهولندا) في حوكمة الجامعات في المملكة العربية السعودية؟ مأبه

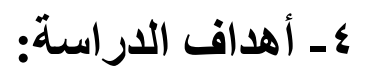

1- التعرف على الأطر النظرية للحوكمة الجامعية في الأدبيات التربوية المعاصرة.

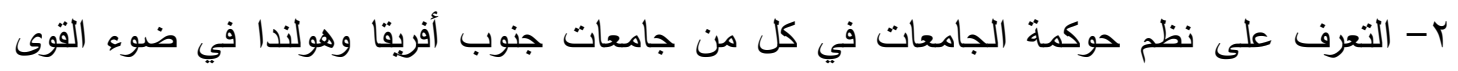
والعوامل الثقافية المؤثرة .

r- التعرف على أوجه الثبه والاختلاف بين نظم حوكمة الجامعات في كل من جنوب أفريقيا وهولندا. ع - التعرف على واقع تطبيق حوكمة الجامعات في المملكة العربية السعودية.

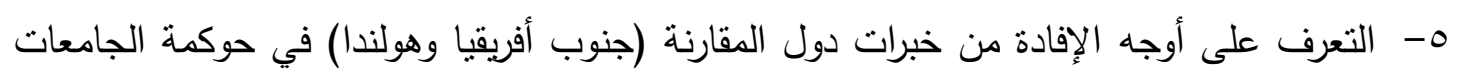

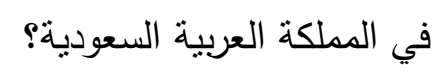

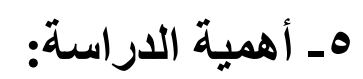

1- تتمثل أهمية الدراسة الموضوع وأهمية دور الجامعات في ظل التحديات التي تواجهها في الواقع المعاصر وضرورة تطبيق الحوكمة ومواكبة الاصلاحات بطريقة فعالة.

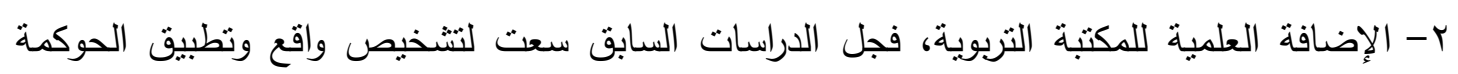
وتقديم تصورات للتطبيق في حين أن الدقارنة بين الدول التي تميزت بالحوكمة والاستفادة منها محلياً غير موجودة.

r- تزايد الاهتمام بموضوع حوكمة الجامعات حيث أن الوعي بهذا المفهوم يؤدي إلى تحقيق وتجويد الممارسات للجامعات من حيث الثفافية والعدالة. 
ـ - يؤمل أن تساهم هذه الدراسة في مساعدة الجهات ذات العلاقة في حوكمة الجامعات السعودية من خلال تزويدهم بالإطار العلمي في دول تميزت بحوكمة الجامعات.

\section{7 - مدود الاراسة:}

1- الحدود الموضوعية: اقتصر موضوع الدراسة الحالية على مقارنة نظم الحوكمة المؤسية للجامعات في كل من جامعات جنوب أفريقيا وهولندا في (أهداف الحوكمة، مبادئ الحوكمة، إجراءات الحوكمة، معايير الحوكمة) للافادة منها في جامعات المعلكة العربية السعودية. ب- الحدود المكانية: اقتصرت على جامعات جنوب افريقيا وهولندا.

\section{V - مصطلحات الار اسةة:}

1- حوكمة الجامعات: تُعرف على أنها الممارسات المنلى التي ترتكز على عدد من المبادئ والمعايير كالثفافية والمساءلة والتنكين والمسؤولية والتي يهدف تطبيقها لرفع مستوى الفاعلية والكفاءة

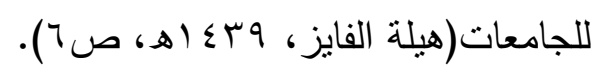

r- وتعرف الباحثة حوكمة الجامعات إجرائياً بأنها ممارسة السلطة من خلال أهداف ومبادئ المؤسسة

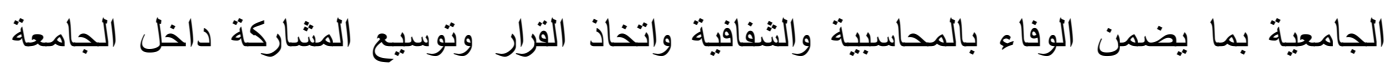

$$
\text { وخارجها. }
$$

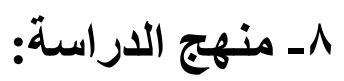

تستخدم الدراسة منهج جورج بيرديGeorge Bereday لدراسة الحوكمة الجامعية في كل من جامعات

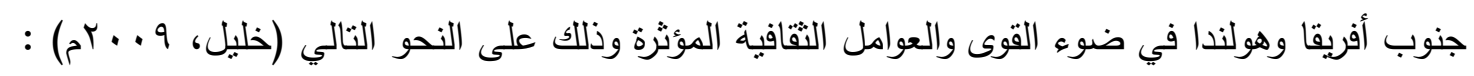
أ- الوصف: وصف الحوكمة الجامعية في كل من جامعات جنوب أفريقا وهولندا من خلال قراءات من

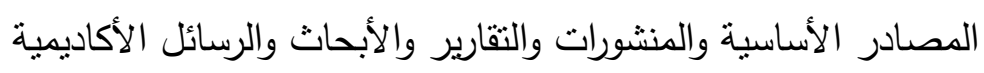

ب- التحليل أو التفسير :تفسير الحوكمة الجامعية في كل من جامعات جنوب أفريقا وهولندا من خلال تتاول القوى والعوامل السياسية والاقتصادية والاجتماعية والجغرافية المؤثرة. 
ج- المقابلة أو الموازنة والمناظرة وهدف هذه الخطوة تحديد أوجه الثبه والاختلاف بين الحوكمة الجامعية في كل من جامعات جنوب أفريقا وهولندا.

د- المقارنة: تلي مرحلة المقابلة ويتم فيها استخلاص أوجه الإفادة من خبرات دولتي المقارنة (جنوب أفربقا وهولندا) في حوكمة الجامعات في المملكة العربية السعودية

ثنانياً:

\section{ـالإطار النظري والدراسات السابقة}

أ) مفهوم الحكومة:

يعد موضوع الحوكمة من الموضوعات الحديثة نسبياً إلا أن جذوره تعود إلى العام بسو ام، وقد زاد الاهتمام بعد حالات التعثر التي واجهتها العديد من الجامعات، ويتحدد مفهوم الحوكمة في ثلاثة مبادئ تساعد على

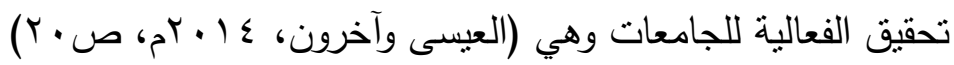

ا- تحقيق الاستقلالية الإدارية بحيث تعنى الجامعات باتخاذ القرارات، ورسم الخطط المستقبلية في ظل

$$
\text { علاقة شراكة مع الحكومة والمجتمع وأصحاب المصالح. }
$$

r- حماية الحرية الأكاديمية للجامعات في إطار قانون الدولة.

r- تحقيق نظام الحوكمة الثفافة وسرعة الاستجابة للمتغيرات.

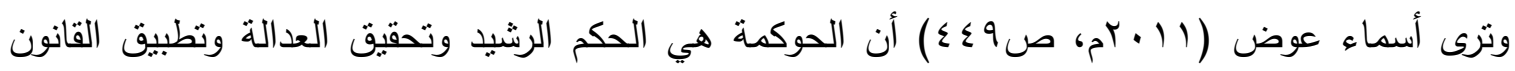
لتحقيق التتمية المستدامة.

كما يثير مصطلح الحوكمة في الجامعات إلى المصدر أو المرجعية التي يستتد إليها في حكم وإدارة الجامعة أو الإطار القانوني والتنظيمي الذي يعمل من خلاله كافة الجامعات المعاصرة من خلال وجود هيئة

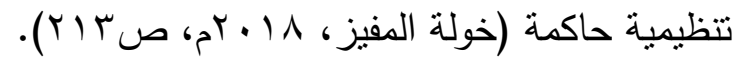

ويعرفها أبو النصر (0 1 • rم) بالإدارة الرشيدة القائمة على النزاهة والثفافية والمساءلة والمحاسبية ومكافحة الفساد، وتحقيق العدالة دون تميز، وتطبيق القانون على الجميع مع توفير رقابة فاعلة داخلية وخارجية. وباستقراء كافة المفاهيم السابقة لمفهوم الحوكمة يتضح: 
- - إن الحوكمة الرشيدة تيسر اتخاذ قرارات تتسم بالعقلانية والاستتارة والثفافية، وتؤدي إلى تحقيق الكفاءة والفعالية على المستوى النتظيمي. - - تثير الحوكمة إلى كيفية تطبيق الأساليب والوسائل التي يتحدد من خلالها توجه الجامعات.

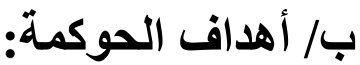

تهدف حوكمات الجامعات إلى تحقيق الانسجام والعدالة الاجتماعية، وترشيد استخدام الموارد الطبيعة والبشرية والمالية، وتحقيق العدالة والإنصاف عبر الكفاءة في تقديم الخذمات، وتوفير وإدامة حالة من

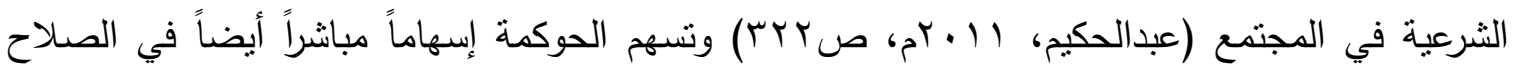

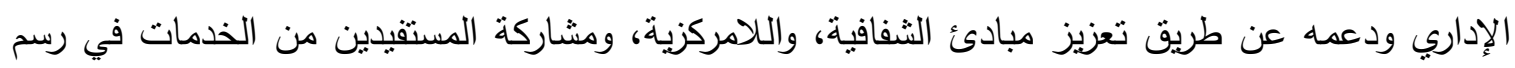

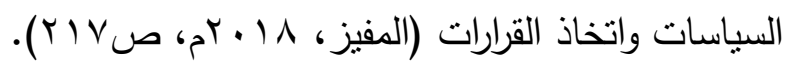

كما تهدف الحوكمة إلى تحقيق الحماية مع مراعاة مصالح العمل والعاملين، والحد من استغلال السلطة في

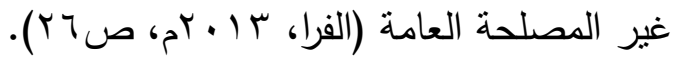

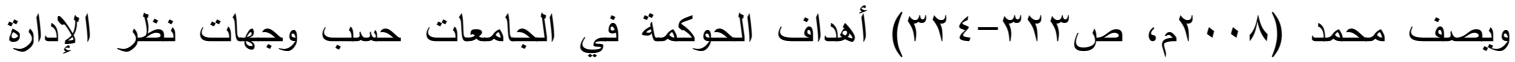

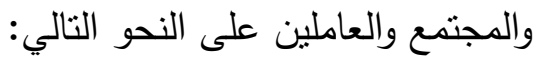

- أهداف الحوكمة من منظور الإدارة: حيث ننظر إلى الحوكمة بأنها تساعد على تعزيز القدرة التتافسية للجامعات، وتحقيق رصانة علمية وتجنب الفساد الإداري والمالي، وتعزيز الثقة بين الأطراف المعينة والقدرة على النطوير . - أهداف الحوكمة من وجهة نظر المجتمع: ينظر المجتمع إلى الحوكمة بأنها رقابة ذاتية وإثنراف ذاتي يؤديان إلى سلامة التطبيق القانوني للتشريعات القانونية والضوابط الحاكمة بضمان حقوق التفان الطلبة وتحقيق رضا المجتمع عن المؤسسة الجامعية. - أهداف الحوكمة من وجهة نظر العاملين: حيث تتضمن الحوكمة الراثندة ضمان حقوق العاملين ومصالحهم بالنظر إلى الإدارة بأنها المعينة بحقوقهم ومصالحهم.

\section{ج) خمسائسم الـحوكمـة :} تتميز الحوكمة المؤسسية بخصائص منها (بيومي والمليجي، (1 + بم، ص1ه): 
- المشاركة : حيث تعتبر المشاركة حجر الأساس في الحوكمة المؤسسية وتبدأ من عمل الأفراد

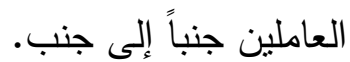
- - سيادة القانون: حيث تنطلب الحوكمة المؤسسية هياكل قانونية عادلة يتم فرضها بثكل نزيه بحيث تتضمن حماية كاملة لحقوق الفرد. - - الثفافية: وتعني أن المعلومات منوفرة ومتاحة للأشخاص المتأثرين بالقرارات ومضمونها وتعني أن هناك معلومات مؤسسية كافية متاحة وسهلة الوصول إليها.

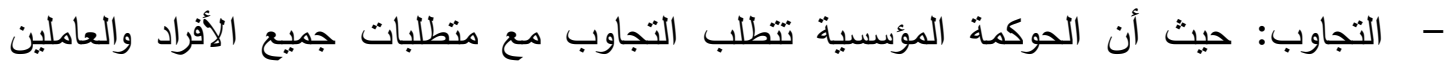
والمؤسسات ضمن أطر زمنية معقولة ومحددة. - التوافق: حيث تتفاوت وجهات النظر بين الأفراد والأقسام ويؤثر بذلك في عوامل متعددة ومختلفة ومتشابكة ولذلك لا بد من التوافق بينها. - - العدل والثمولية: فوجود نظام عادل يعتمد على ضمان أن جميع المعنيين لايهم دور في هذا النظام وينطلب ذلك مشاركة من جميع فئات المجتمع.

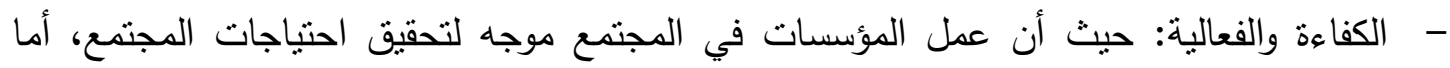
الكفاءة فتعني الاستغلال الأمثل للموارد المتاحة. - المساءلة والمحاسبية: فالمساءلة تعد عاملاً مهماً ومؤثراً في فعالية الحوكمة.

\section{د) معوقات تطبيق الحوكمة بالجامعات:}

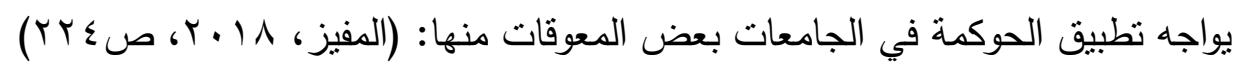

- - ضعف العلاقة بين أعضاء هيئة التدريس وبين الإدارة الجامعية، وانخفاض مستوى الرضا الوظيفي

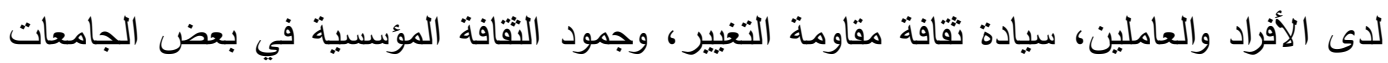

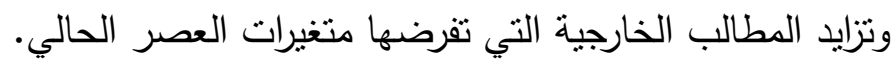

ويضيف عزت (9 . +rم، ص ץ-r) أن من معوقات حوكمة الجامعات الثقافة السائدة في المجتمع: كالقيم السليية، ومقاومة التغيير، والتتريعات الجامعية، وطريقة إدارة الجامعة كأسلوب التعيين ابتداء من رئيس

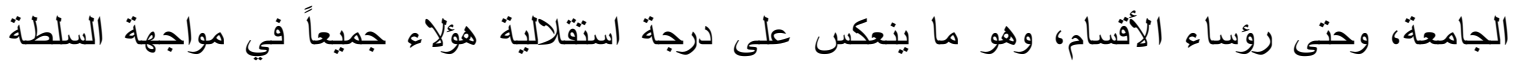
التتفيذية، وغياب أعضاء هيئة التدريس عن الحياة الجامعية، وكذلك غياب التنظيمات المستقلة والخاصة بأعضاء هيئة التدريس والطلاب عن منظومة الجامعة. 
هناك العديد من البحوث والدراسات التي تتاولت الحوكمة في التعليم العالي إلا أن الدراس الحالية مختلفة،

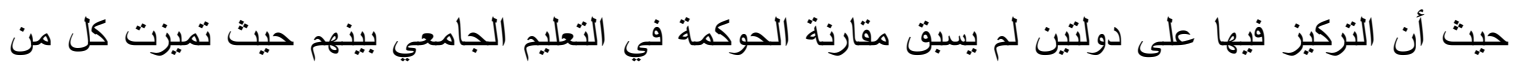
جنوب افريقيا وهولندا بارساء قواعد الحوكمة في إدارة شئون الجامعات. ونم الرجوع إلى العديد من الدراسات السابقة وعرضها وفق التسلسل التاريحي من الأحدث إلى الأقدم. 1- دراسة (خولة المفيز، 11 • بام) هدفت هذه الدراسة إلى التعرف على واقع تطبيق الحوكمة في

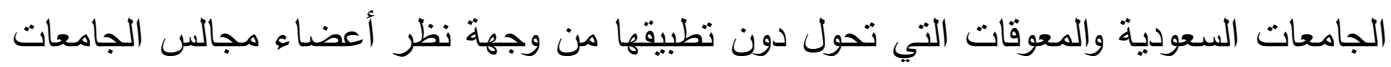

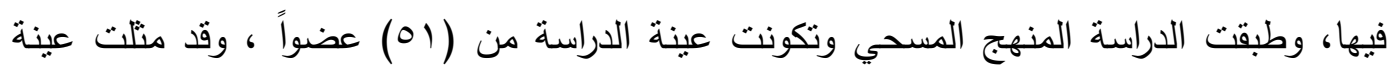

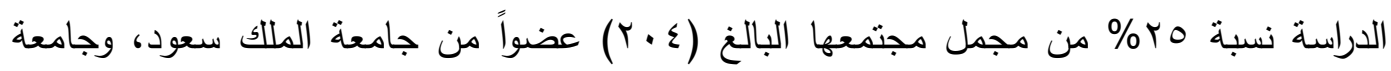

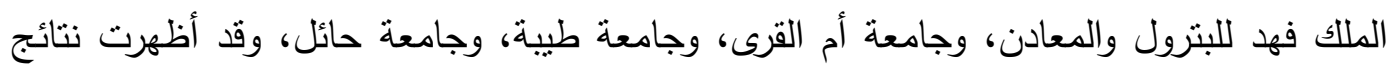

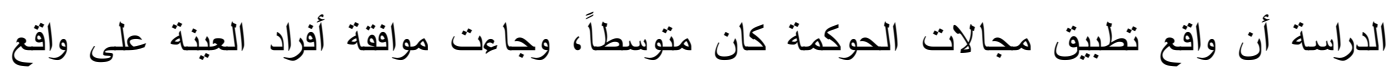

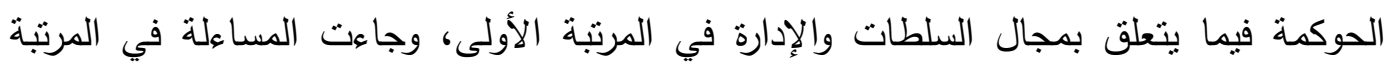

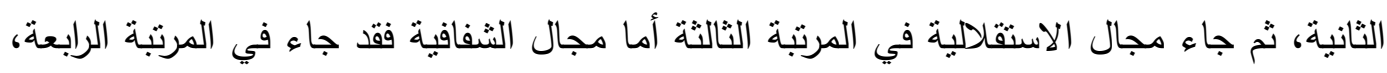
ثم جاء مجال المشاركة في المرتبة الخامسة والأخيرة ، كما أظهرت النتائج أن موافقة عينة الدراسة

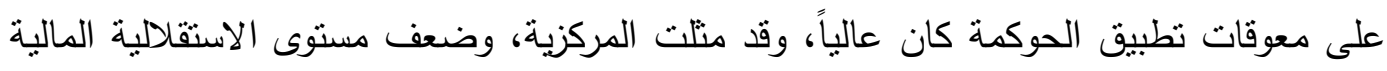
والإدارية وتدني مستوى الحرية الأكاديمية أبرز المعوقات دون تطبية تطبيق الحوكمة في الجامعات

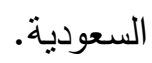

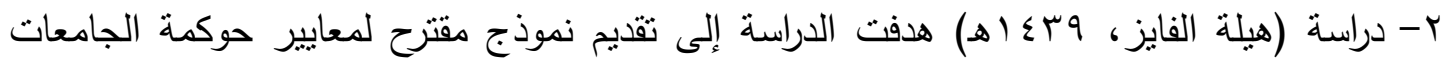
الحكومية السعودية وفق أبعاد المنظور الاستراتيجي للحوكمة، ولتحقيق هدف الدراسة نم استخدام

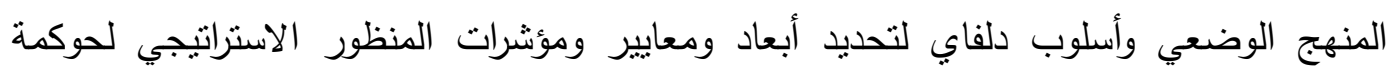

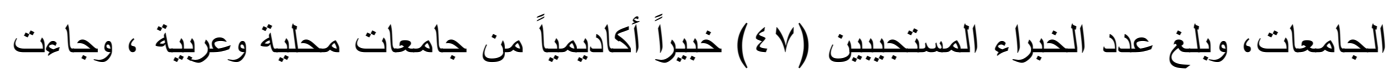
أبعاد حوكمة الجامعات الحكومية السعودية وفق المنظور الاستراتيجي كالتالي: البعد الرقابي

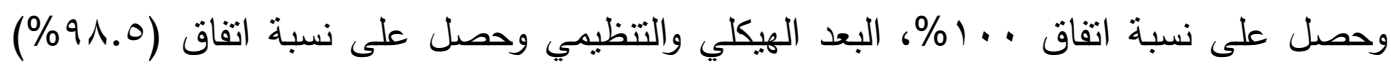

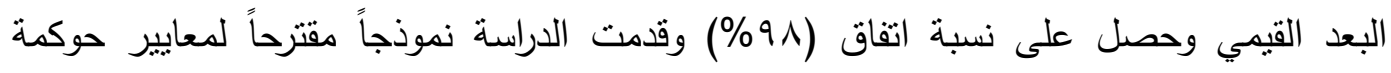
الجامعات السعودية وفق المنظور الاستراتيجي تضمن مرتكزات وأهداف ومكونات الاستراتيجية ونطاق التطبيق ومنطلباته ومراحله وأدواته. 


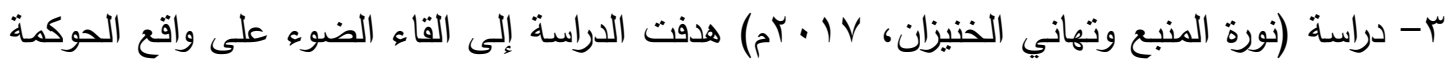

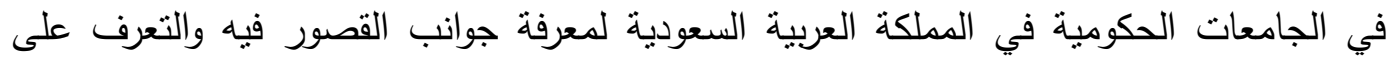

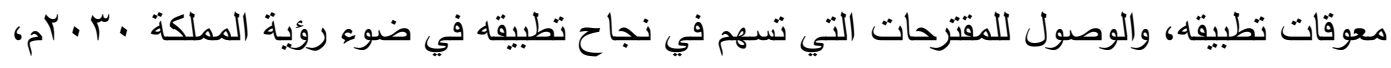

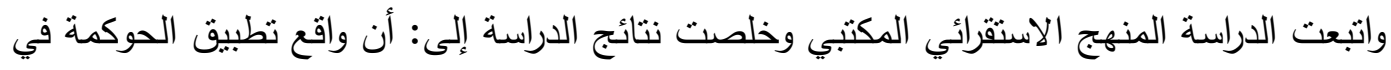

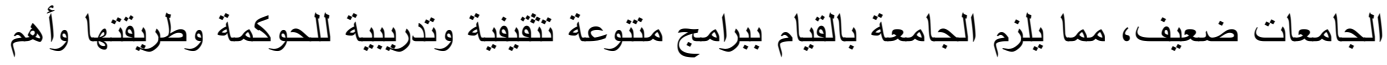

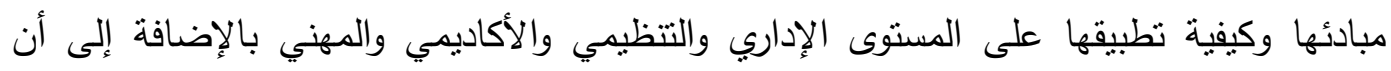
القيادات الأكاديمية تدرك وبقوة مفهوم وأهية تطبيق الحوكمة، مما يوجب انشتراكها في بناء معايير خاصة لحوكمة كل جامعة تتناسب مع وضعها وأن متطلبات تطبيق الحوكمة مهمة وتتضمن: بناء هيكل تتظيمي تحدد منه السلطات والصلاحيات والمهام الوظيفية، وتفعيل دور مجالس الكليات

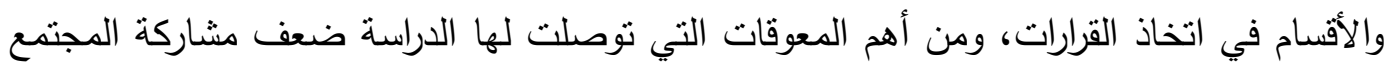

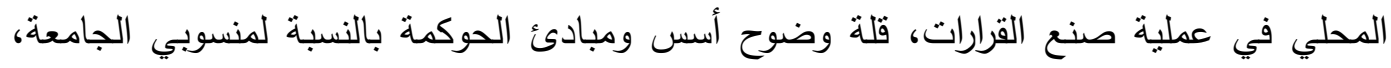

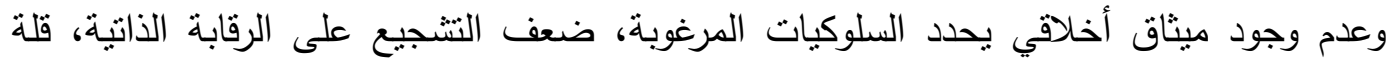

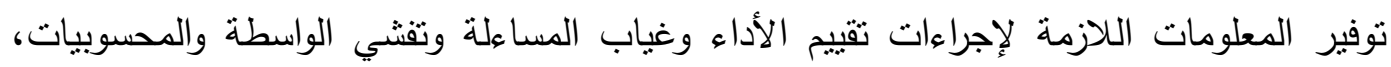
وأخيراً ضعف قدرات الجامعة على تحقيق الأهداف التي وضعت من ألجاءها.

ع - دراسة (هيا الإبراهيم، 10 • rم) هدفت إلى التعرف على واقع الحوكمة وتحدياتها في وزارة التعليم

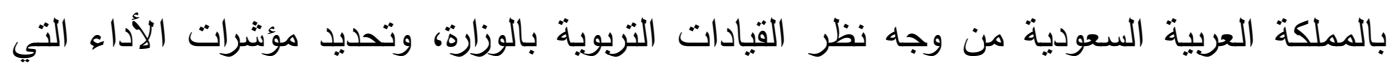

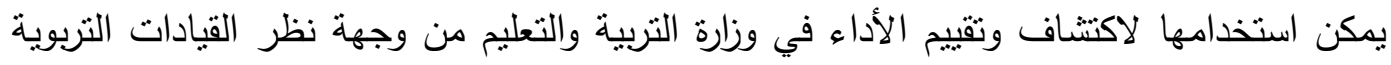

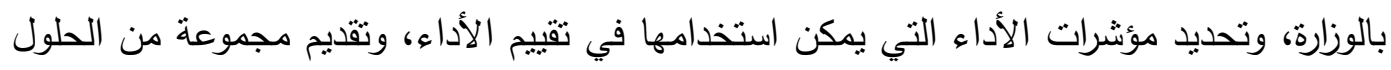

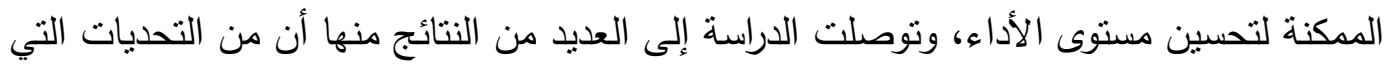
تواجه تطبيق الحوكمة غياب المعايير في اختيار القيادات الإدارية.

0- دراسة (السوداي، 10 •rم) هدفت هذه الدراسة إلى بناء تصور مقترح لنطبيق الحوكمة الرشيدة كمخل لضمان الجودة والاعتماد الأكاديمي في الجامعات السعودية، وقد استخدم الباحث الدنهج الوصفي المسحي وتم تطبيق الاستبانة على القادة الأكاديميين في خمس جامعات حكومية، وقداد الادي أظهرت النتائج أن القيادات الأكاديمية يدركون بدرجة عالاية جدية علداً مفهوم الحوكمة، وأهمية تطبيق 
الحوكمة ، وأن هناك معوقات عديدة تواجه تطبيقها وإن واقع تطبيق الحوكمة في الجامعات

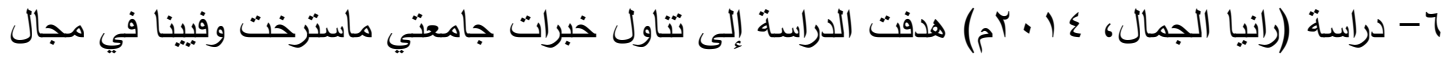

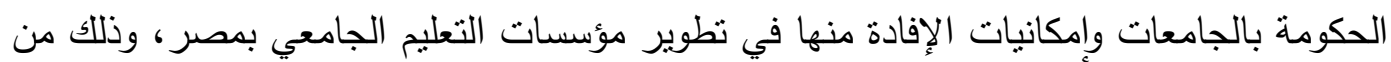
خلال توضيح الأسس النظرية لحوكمة الجامعات والتعرف على ملامح وأسس الحوكمة في جامعتي الإني المقارنة والوقوف على واقع الجهود المصرية في هذا المجال، ومن ثم تقديم اجراءات مقترحة لتفعيل الحوكمة بالجامعات المصرية بما يتتاسب وظروف المجتمع المصري وأوضاعه الثقافية وطبقت

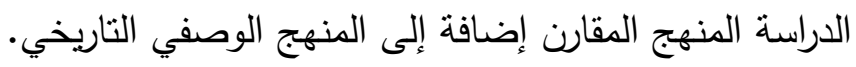

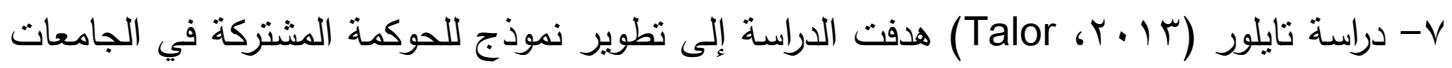

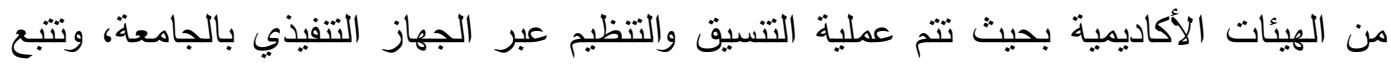
الباحث في الدراسة تطور الحوكمة المشتركة بين الهيئات الأكاديمية في المملكة المنحدة منذ عام

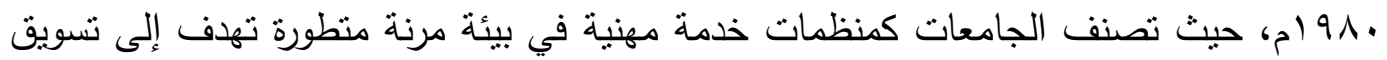

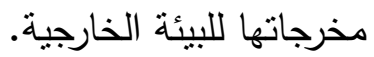

^- دراسة موك (Mok, 2010) حول الجامعات في سنغافورة وماليزيا ومدى تطبيقها للحوكمة، وكيفية

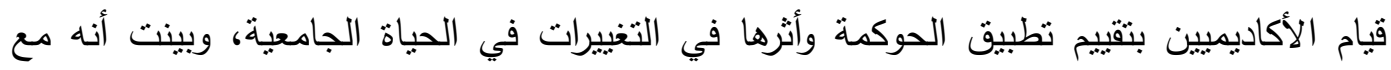
الإدارة العليا لهذه الجامعات أعطيت بعض الحرية لكيفية إدارة جامعانهم، إلا أن معظم الأكاديميين

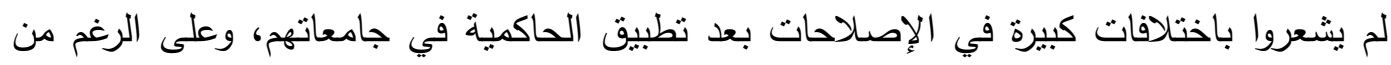

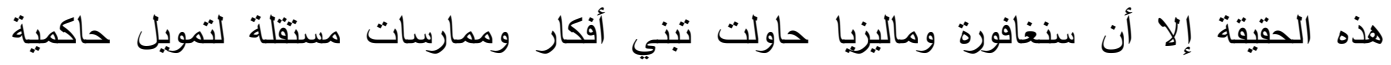
الجامعات، لأن الأكاديميين برون أن الدولة لا تزال غير قادرة على مراقبة الجامعات والتعليم العالي.

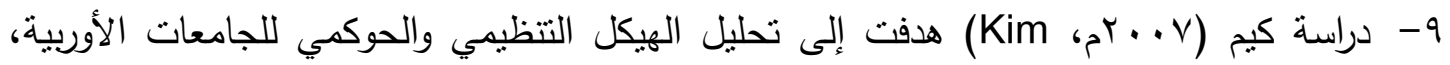
وتحديد إطار العمل القائم على التبؤ بالسمات الرئيسية في المؤسسة، وقد وصفت الدراسة عدة التئ 
سمات كانت محلاً للبحث والتحليل منها: نموذج الحوكمة والهيكل التتظيمي، وطبقت الدراسة على في

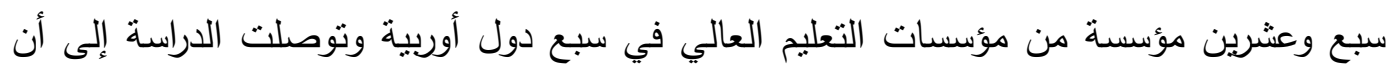

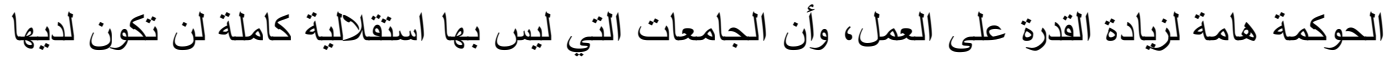

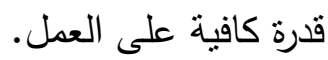

\section{التعقيب على الاراسات السابقة:}

الدراسات السابقة تبين بوضوح أهمية نطبيق الحوكمة في الجامعات، واتققت الدراسة الحالية مع الدراسات السابقة في واقع تطبيق الحوكمة مثل دراسة (خولة المفيز، 11 ـ بام) ودراسة (نورة المنيع وتهاني الخنيزان،

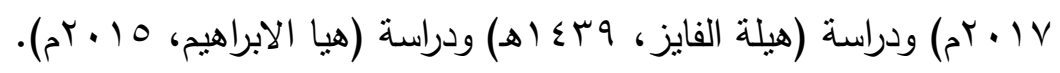

كما اتقتت الدراسة في منهج الدراسات المقارنة بين الدول ومدى الافادة منها مثل دراسة (رانيا الجمال،

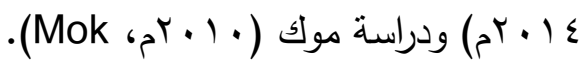

واختلفت الدراسة الحالية عن الدراسات السابقة في بعض الجوانب منل دراسة (السوادي، 10 • rم) التي هدفت إلى بناء تصور مقترح لنطبيق الحوكمة كدخل لضمان الجودة والاعتماد الأكاديمي في الجامعات السعودية.

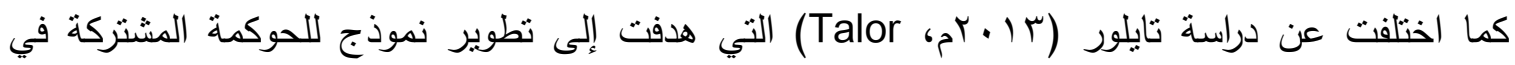

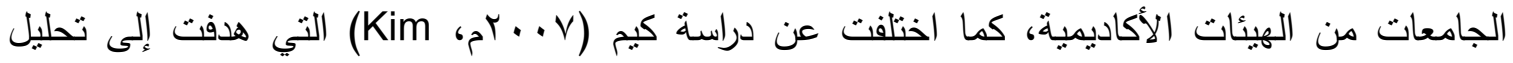

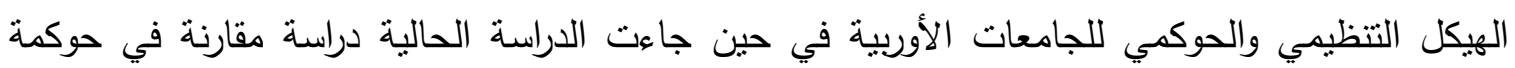

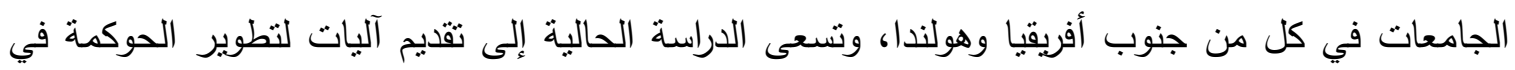

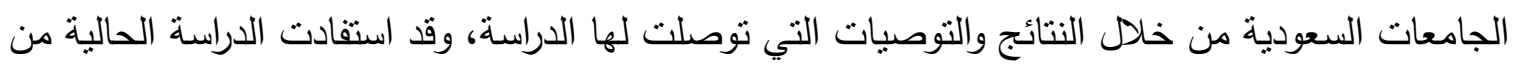
الدراسات السابقة في بعض الجوانب رغم تتوعها واختلاف مناهجها في التأكيد على أهمية الدراسة الحالية

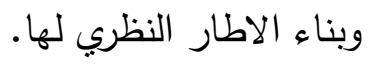




\section{ثُالثاً: خطوات البحث وإجراعاته}

تتضمن الإجراءات تحليل القوى والعوامل المؤثرة على الحوكمة في دول المقارنة ومن ثم تحديد أوجه التثابه

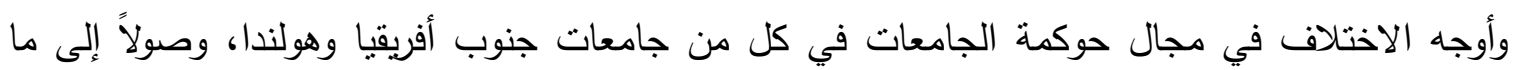
يمكن الأخذ به أو الإضافة إليه أو تعديله، وما يقتضي ذلك من إحداث التغيير والتطوير لتطوير الحوكمة التهال في التعليم الجامعي في المملكة.

\section{القوى والعوامل التي تؤثز على الحوكمة المؤسسية للجامعات}

أولاً:

أ) التطور التاريخي للحوكمة المؤسسية بجنوب أفريقيا (ضحاوي والمليجي، ال ـ بم،

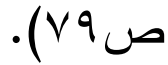

شهر النصف الثاني من القرن العشرين توسعاً كمياً كبيراً في التعليم الجامعي، وذلك من جهة تزايد الطلبة

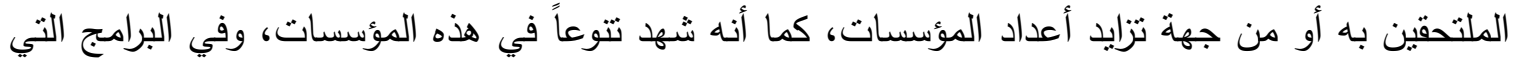
تقدمها وتبعث الحاجة لتحسين نوعية التعلم الجامعي من مصادر داخلية وخارجية جعلت من مسألة اعتماد نظم الحوكمة المؤسسة والجودة تمثلل مكانة بارزة على المستويات الوطنية.

وترجع الارهاصات الأولى لبدايات الحوكمة المؤسسة إلى العقد التاسع من القرن العشرين كاستجابة لعمليات

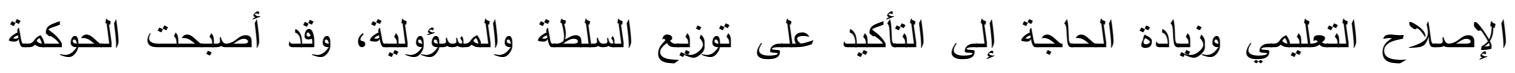
المؤسسية بمثابة ميكانيزم للامركزية، وتوسيع المشاركة المجتمعية، ففي عام ؟ 99 ام تم القضاء على حكم

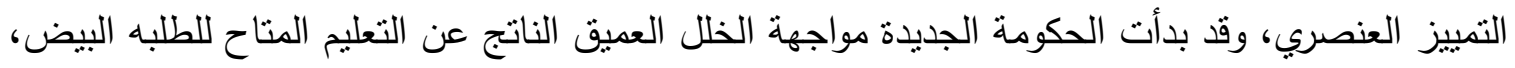
وشبه التعليم الذي ينلقاه الطلبة السود.

حيث احتل التعليم بوجه عام والتعليم الجامعي بوجه خاص جزء كبيراً من مسيرة النضال ضد التمييز العنصري، كما شكل أولوية للحكومات المتعاقبة على البلاد وتم تخصيص ـ ب\% من الموازنة العامة السنوية

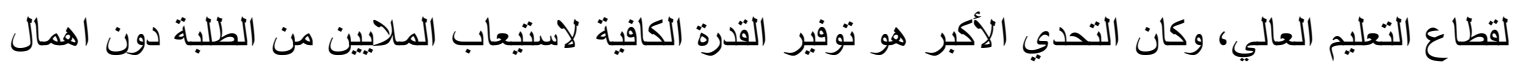

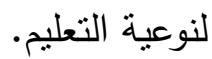

وتلى ذلك تأكيد للجنة القومية للتعليم العالي على إعادة هيكلة التعليم الجامعي واتاحته للجميع والتخطيط لجودته، والتوجه نحو ما يعرف بـ (الحوكمة التعاونية) كنموذج لحوكمة الجامعات على مستوى النظم 
والمستويات المؤسسية، وأكدت السياسة القومية للتعليم على ضرورة الاستفادة من تجربة الولايات المتحدة

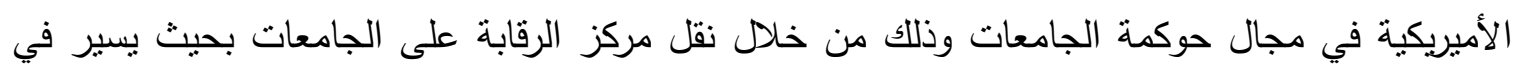
اتجاهين أولهما على المستوى القومي ويتمنل في وضع الأهداف وتطوير المناهج وضع متئ معايير التقييم

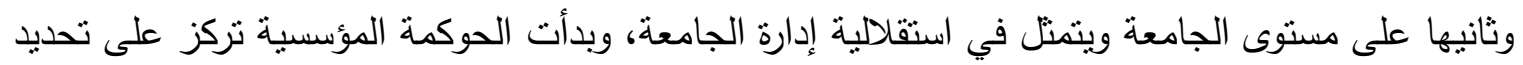
الأدوار والقواعد، وربط السلطة الإجرائية في الجامعات بآليات الحوكمة.

ويعد عام 997 ام نقطة الانطلاق الملائمة لاعادة النظر في سياسات التعليم الجامعي في جنوب أفريقيا

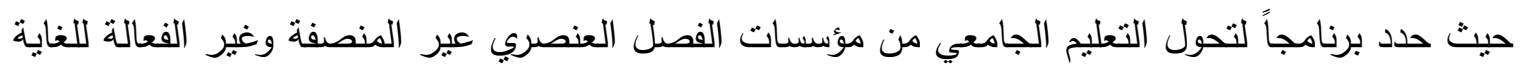
إلى نظام واحد يخدم كل الاحتياجات الفردية والجماعية.

وفي عام l . بr تم وضع الخطة القومية لنطوير التعليم العالي، والتي تضمنت بعض مشروعات النطوير،

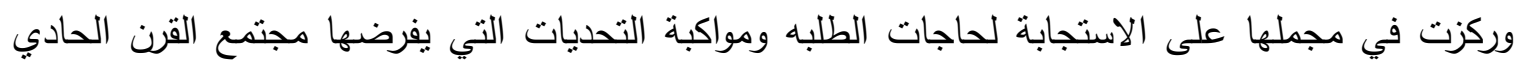
والعشرين وصاحب ذلك نغير النظرة إلى التعليم الجامعي حيث أصبح ينظر إليه على أنه ضروري لتحقيق

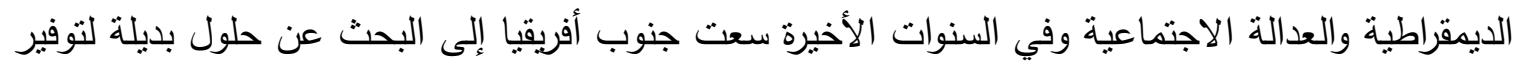

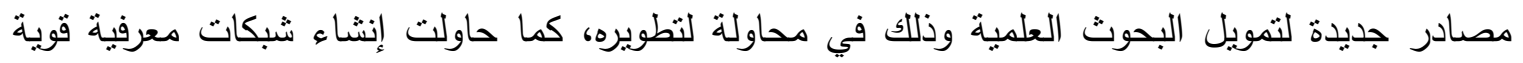

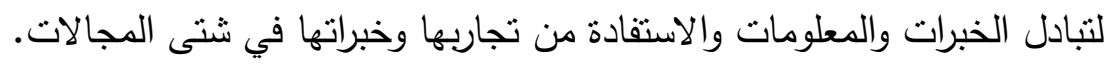

مما سبق يتضح أن تطوير التعليم الجامعي وتحديثه من خلال تطبيق الحوكمة المؤسية والجودة يحظى الجي

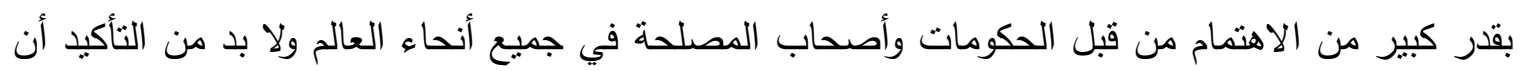
جنوب أفريقيا لديها القدرة التعليمية على مواجهة التحديات المحلية والعالمية في العقود القادمة.

\section{ب) التطور التاريخي للحوكمة في هولندا (رانيا الجمال، ع ( ب إ، ص •0)}

منذ الحرب العالمية الثانية زاد اهتمام الحكومة الوطنية الهولندية بالتعليم العالي واعتبر هذا التطور لا مفر

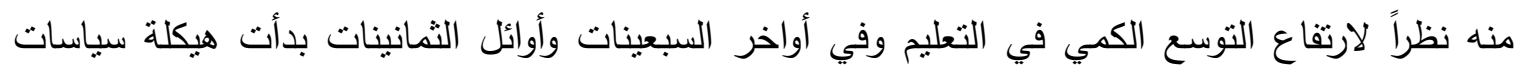

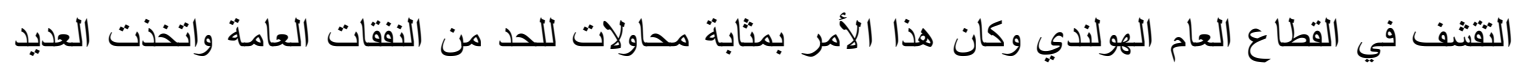
من الإصلاحات مفهوم "التوجيه من بعد" ويعرف هذا المفهوم باسم فلسفة Hoak: أبي استقلالية النعليم العالي والجودة إلا أن تتظيم الدولة لم يختفي.

ولقد انعكست الظروف التاريخية وما صاحبها من ظروف ومتغيرات على علاقة الدولة بجامعاتها، فالجامعات والكليات لديها مساحة كبيرة من الاستقلال ولا تتذخل الدولة في شئونها وتعمل سياسة مملكة 
هولندا في إطار برلماني ديمقراطي في ظل دستور ملكي ودولة مركزية وتتميز السياسة والحكومة الهولندية

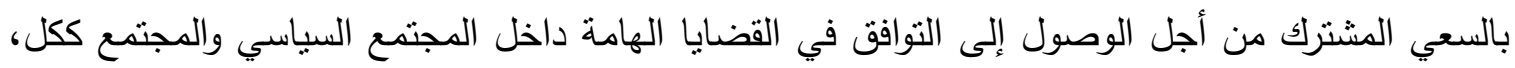
وهولندا دولة ملكية ودسنورية والدستور يمنح المللك سلطة محددة ومقر الحكومة في لاهاي.

ويتمتع النظام السياسي والإداري في هولندا بمستوى عال من النقة المتبادلة بين القادة السياسيين والإداريين، وداخل الإدارة العامة وقد أثرت هذه العوامل السياسية على التعليم بالجامعات حيث شهدت الحوكمة

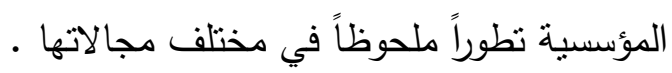

وتعكس بداية عام 910 ام التحول من الحكومة إلى الحوكمة في مؤسسات التعليم العالي الهولندي بما

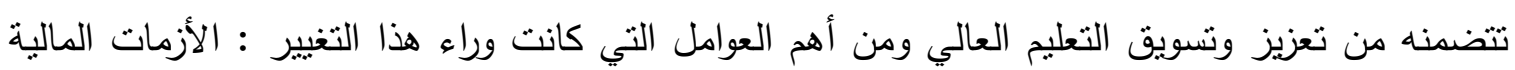

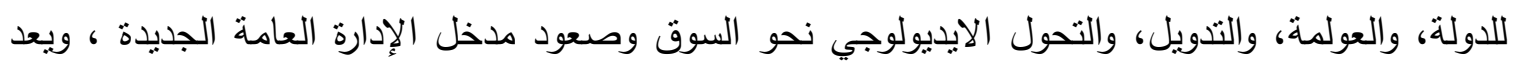
هيكل الحوكمة الداخلية للجامعات أحد أهم الإصلاحات الرئيسية في ولئيل هولندا.

\section{ثانياً:}

\section{أ) أهداف الحوكمة المؤسسية بجنوب افريقيا (ضحاوي والمليجي، ( 1 ـ كم، صسمر)}

تتمثل أهداف الحوكمة المؤسسية في جامعات جنوب أفريقيا في : تحقيق وتميز وجود الإدارة الجامعية،

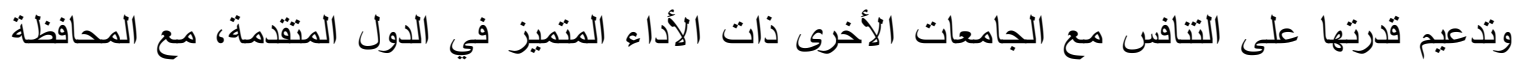
على الاستقلالية، دون الاعتماد على الطرق والمداخل التي تؤكد على مركزية التخطيط والإدارة في

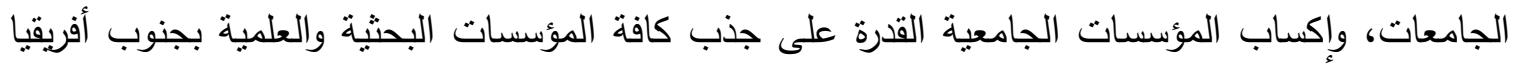

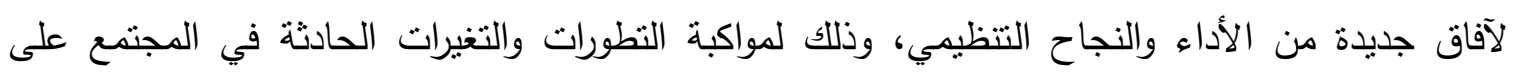
المستوى المحلي والدولي واعادة ترتيب الأولويات المالية وترشيد الإتفاق على التعليم الجامعي.

كما تهدف الحوكمة المؤسسية للجامعات في جنوب أفريقيا إلى تفعيل نظم المحاسبية والمساءلة التعليمية لكل

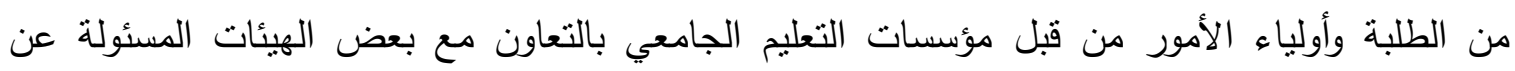

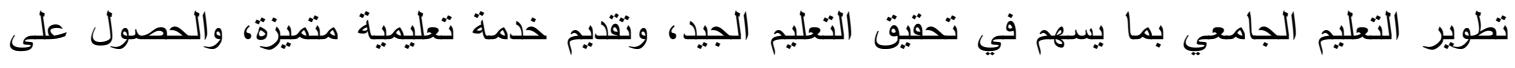

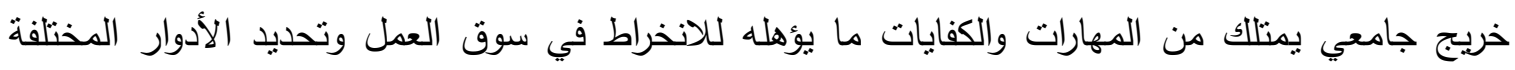

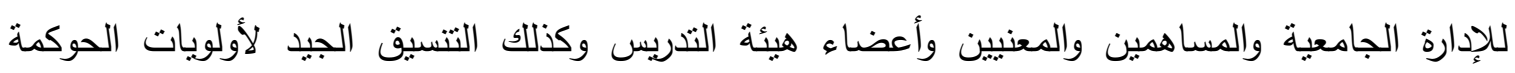

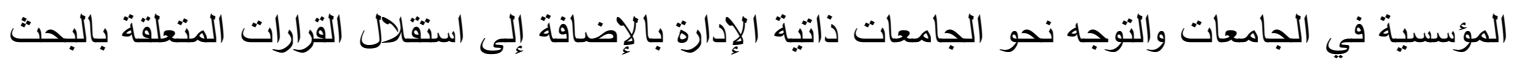

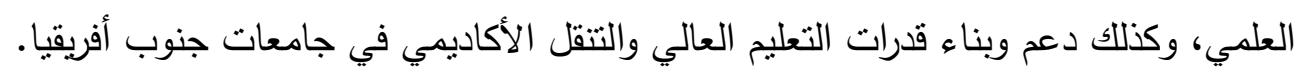




\section{ب) أهداف الحوكمة المؤسسية في هولندا (رانيا الجمال، ـ ( بام، ص^ץ؟)}

لعبت الحوكمة الوطنية الهولندية دوراً تقليداً مهماً في تتسيق بحوث التعليم العالي، وقد اعتبر التعليم العالي

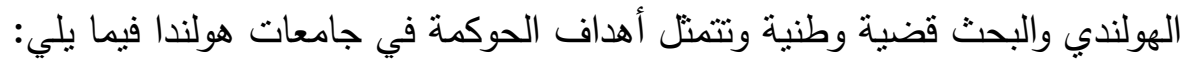

$$
\begin{aligned}
& \text { - تركز القوى من حيث تكامل الحوكمة وسلطات الإدارة } \\
& \text { - - مزيد من الثفافية في علاقات السلطة } \\
& \text { - - ميادة فعالية صنع القرار }
\end{aligned}
$$

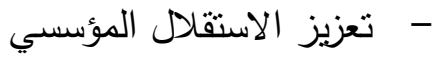

$$
\begin{aligned}
& \text { - - تميز وجودة الإدارة الجامعية والتعليم والبحث التيفي }
\end{aligned}
$$$$
\text { - - الحفاظ على مشاركة كبيرة من الطلاب والموظفين في صنع القرار • }
$$

وبالنظر إلى الأهداف السابقة يتضح أن خطط جامعات هولندا من أجل تفعيل الحوكمة تنلورت في ثلاث مجالات. وهي جودة التنريس، والبحث، وتنظيم مشاركة كاملة من الموظفين والطلبة.

\section{ثُالثثاً:}

\section{أ) مبادئ الحوكمة المؤسسية بجنوب افريقيا (ضحاوي والمليجي، ( 1 • كم، صبر)}

تعتمد الحكومة المؤسسية في جنوب افريقيا على عدة مبادئ بأتي في مقدمتها: نطوير الأطر المؤسسية

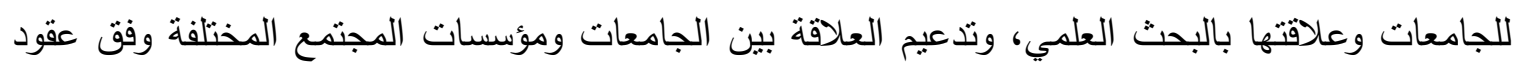

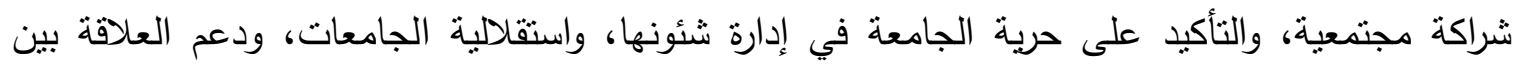

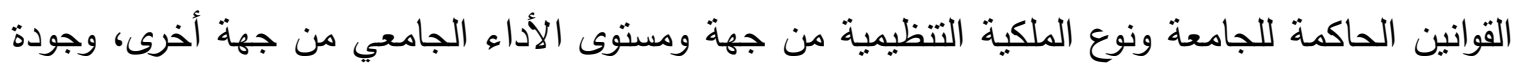

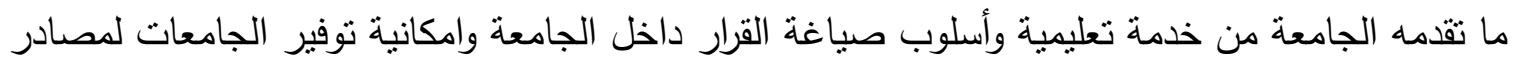

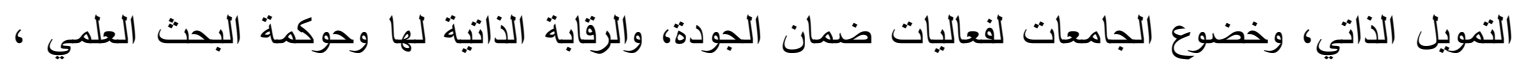
ووضع بعض المعايير والمؤشرات الخاصة بتقييم الأداء الجامعي واعتمدت الحوكمة على عدة مبادئ منها:

$$
\text { - - - معالية مشاركة أصحاب المصالح - }
$$

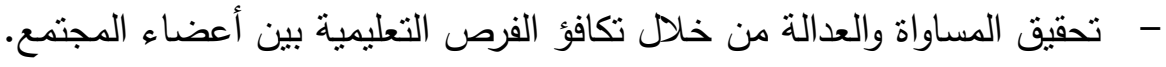

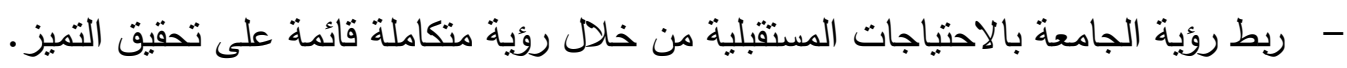

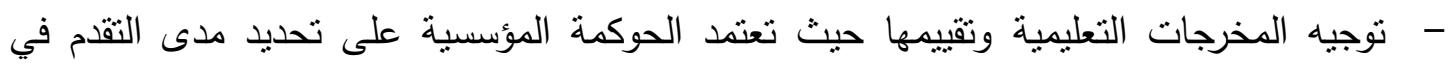

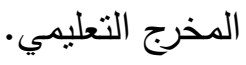




\section{ب) مبادئ الحوكمة المؤسسية في هولندا (رانيا الجمال، ع ا ـrم، صr \&)}

تتحدد مبادئها في تعزيز الاستثمارات في المواهب وتحقيق نشر المعرفة، تعزيز التعاون الدولي، وتتنهج

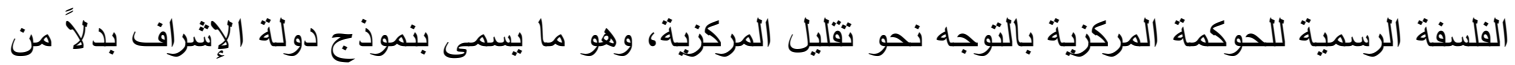
ن موذج سيطرة الدولة.

فالجامعات الهولندية تعمل بفعالية فيما يتعلق بالابتكار والتتافس في الخدمات التعليمية، كما شهدت الجامعات الهولندية تغيرات جعلنها تأخذ شكل شركات بصورة أكبر، فنتيجة لاصلاحات الحوكمة أصبحت الجامعات الهولندية توصف بأنها جامعات شركات حيث اكتسبت قدرات العمل على مستوى الثركات وقدرة على اتخاذ قرارات استراتيجية والتصرف بسرعة.

رابعاً:

\section{أ) اجراءات الحوكمة في جنوب أفريقيا}

تتم الحوكمة المؤسسية بجنوب أفريقيا على مستوبين: أولهما الأطر القومية لحوكمة الجامعات، حيث تؤكد أن الحوكمة يجب أن تكون مناسبة للإدارة العليا والممارسات الادارية بالوحدات القومية وثانيهما: الحوكمة المحلية للجامعات حيث تتم من خلال تعيين مجلس لحوكمة الجامعات والذي بدوره يحاول تدعم

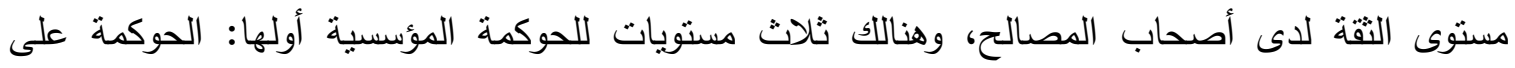
مستوى النظام وثانيهما الحكومة المؤسسية بين الجامعات وثالثهما: الحوكمة المؤسسية على مستوى الجامعة

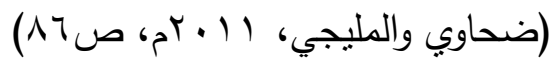

$$
\begin{aligned}
& \text { ب) إجراعات الحوكمة في هولندا }
\end{aligned}
$$

ينص القانون إن إجراءات الحوكمة في هولندا تتحدد في أجهزة الإدارة العليا الحاكمة للجامعة وهي كالتالي

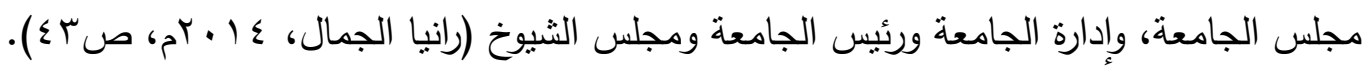

خامساً:

\section{أ) معايير الحوكمة المؤسسية للجامعات في جنوب افريقيا}

تتم حوكمة مؤسسات التعليم الجامعي في جنوب افريقيا وفق مجموعة من المعايير التي نتطرق لجميع جوانب المؤسسة الجامعية وتتمثل المعايير في : 
- تطبيق المؤسسة السياسات والإجراءات التي توفر التوجيه والتدريب.

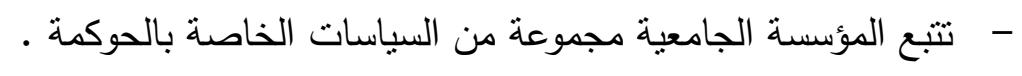

-

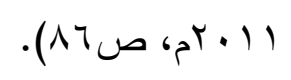

\section{ب) معايير الحوكمة المؤسسية للجامعات في هولندا}

التنظيمات المسئولة عن الثنفافية وتدفق المعلومات في هولندا تتص على ضمان الجودة وتطبيق المعايير

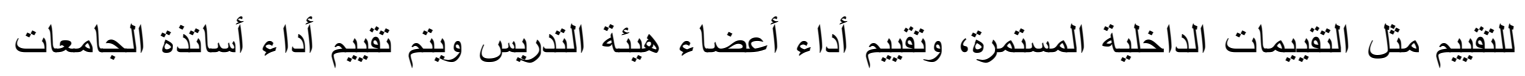

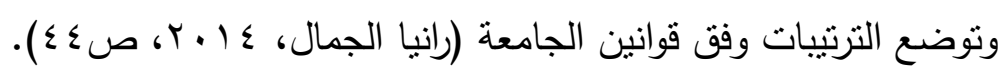

\section{رابعاً: تحليل مقارن لنظام الحوكمة المؤسسية للجامعات في كل من جنوب

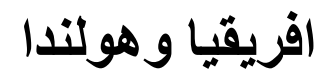

\section{/ / القوى والعوامل الثقافية التي تؤثر على الحوكمة المؤسسية للجامعات \\ أوجه التشابه:

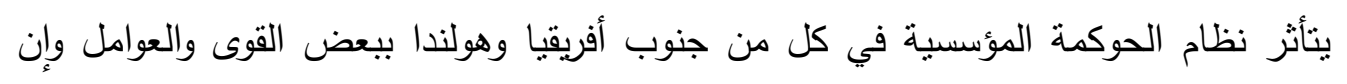

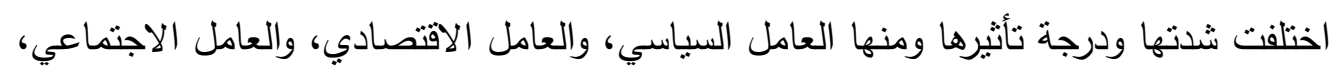

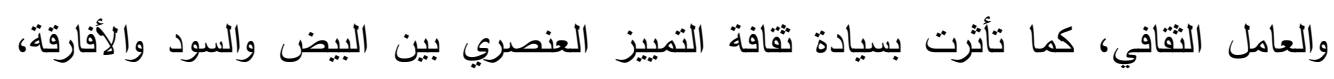

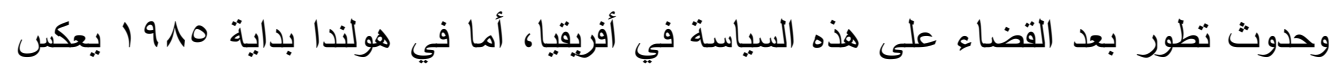

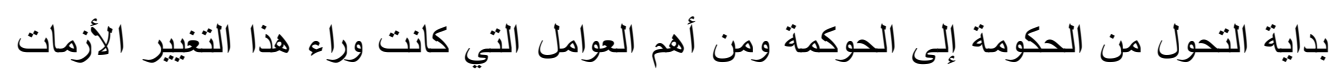

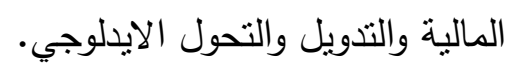

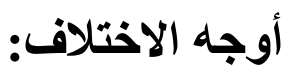

تتضح أوجه الاختلاف فيما أسهمت به هذه القوى والعوامل من وجود اختلافات فيما يخص الحص

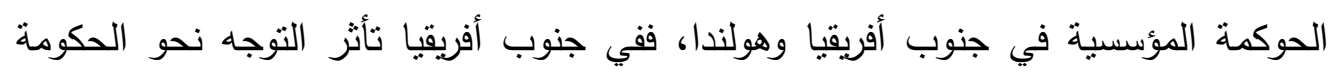
المؤسسية. بالجانب الاقتصادي ، وما نتج عنه من إصلاحات في التعليم الجامعي وأيضاً فترة الانتقال بين عصر العنصرية إلى الحكم الجمهوري أثر على حوكمة الجامعات. 
أما في هولندا فإن الازدهار الاقتصادي ساهم في تعزيز وتوفير الخدمات التعليمية والبحثية والمجتمية لأنشطة الجامعات وتحسين جودة التعليم الجامعي بالإضافة إلى تمتع الجامعات بحق تعنيز تعيين أساتنتها دون تدخل من سلطة خارجية.

\section{ץ أهداف الحوكمة المؤسسة}

بعد استعراض أهداف الحوكمة المؤسية في جنوب أفريقيا وهولندا يمكن استتتاج ما يلي:

أوجه التثابه:

(ا)

تتثابه أهداف الحوكمة المؤسسية في جنوب أفريقيا وهولندا، حيث تهدف إلى نحقيق الجودة في

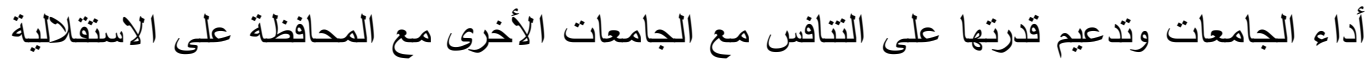
واكساب المؤسسات الجامعية القدرة على جذب كافة المؤسسات البحثية.

وتهدف الحوكمة المؤسسية للجامعات في جنوب أفريقيا وهولندا إلى تفعيل نظم المحاسبة والمساءلة التعليمية وتعزيز الاستقلال المؤسسي وزيادة فعالية صنع القرار.

يوجد اختلاف في أهداف الحوكمة المؤسسية في جنوب أفريقيا وهولندا ففي جنوب افريقيا تهدف

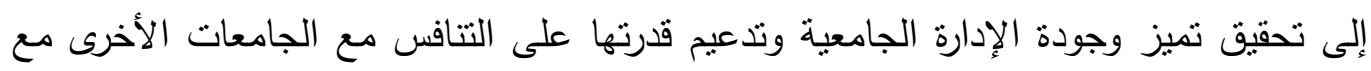

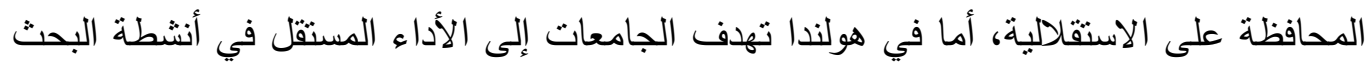

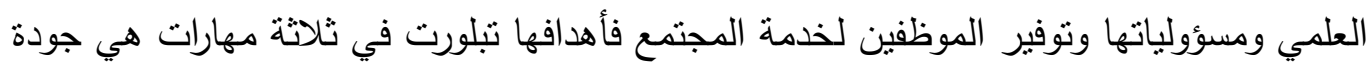
التدريس، والبحث، وتنظيم ومشاركة الموظفين والطلاب .

\section{ץ) مبادئ الحوكمة المؤسسية

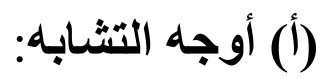

تتشابه مبادئ الحوكمة المؤسسية في جنوب أفريقيا وهولندا بوضع خطة للتمويل الذاتي بالجامعة والاتصال

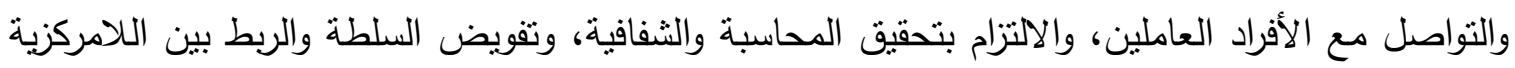

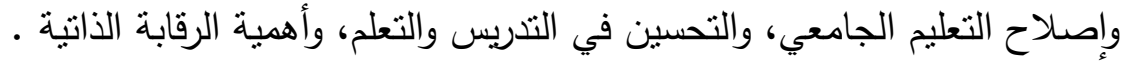




\section{(ب) أوجه الاختلاف:}

يوجد اختلاف في مباديء الحوكمة المؤسسية في جنوب أفريقيا وهولندا، ففي جنوب أفريقيا تتمنل في وضع سياسات واضحة للحوكمة، وقيام الجامعات بتضمين أنشطة الحوكمة في عملياتها، وربط الحوكمة بسياسات الجامعة، وتهيئة ظروف مناسبة لتحقيق وظائف حوكمة مؤسسات التعليم الجامعي بالكفاءة والفعالية، أما في جنوب هولندا فتتمتل في ادخال هيكل باما (Bama) لاستحداث هياكل وتفعيل الحوكمة الداخلية والخارجية للجامعات وهو ما انعكس على الجامعات بأن تتوجه نحو نقل العديد من المسئوليات التي تضطلع بها الحكومة إلى الجامعات ذاتها فيما يتعلق بالتمويل، وضمان الجودة، وسياسات شئون الموظفين، وكذلك إحالة

القوى المركزية إلى رئيس الجامعة وشئون الموظفين لتكون الجامعة قادرة على سياق المنافسة.

\section{ع - اجراءات الحوكمة المؤسسية واستراتيجياتها}

أوجه التشابه:

(l)

وتتمثل في نطوير الأطر المؤسية والأكاديمية بالجامعات للتفاعل مع آليات ندويل التعليم

الجامعي ووضع نظم منطورة لتحفيز مؤسسات التعليم الجامعي، على تتويع مصادر تمويلها، وانشاء برامج أكاديمية مشتركة مع القطاع الخاص المحلي والجامعات الأجنبية

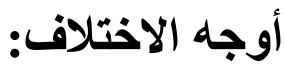

يوجد اختلاف بين نظم الحوكمة المؤسسية في جنوب أفريقيا وهولندا ففي جنوب أفريقيا تتم الحوكمة على مسنويين هما الأطر القومية لحوكمة الجامعات والحوكمة المحلية للجامعات وتوجد ثلات مسنويات للحوكمة المؤسيسة لجامعات جنوب أفريقيا وهي الحوكمة على مستوى النظام، والحوكمة المؤسسية بين الجامعات، وكذلك الحوكمة على مستوى الجامعة.

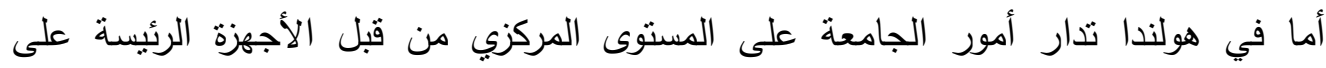
المستوى المركزي وتتمثل في جهاز الرقابة والمجلس التتفيذي ومجلس الجامعة ومجلس

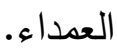

وتتمنل الحوكمة الخارجية في الأجهزة الوطنية وهي وزارة المالية وزارة الثئون الاقتصادية ووزارة التربية والتعليم والثقافة والعلوم، ووزارة الزراعة والطبيعة. وجودة الخطة الاستراتيجية للمؤسسة، والتنظيمية المسئولة عن الثنفافية وتدفق المعلومات ومن أهمها هيئة ضمان الجودة. 


\section{• - معايير الحوكمة المؤسسية:}

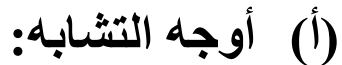

تتمثل في أن معايير الحوكمة المؤسسية في دول المقارنة تنطرق لجميع عناصر المنظومة الجامعية، كما يتم تصنيف هذه المعايير في شكل معايير أساسية، يندرج تحت كل معيار منها عدد من المؤشرات والمعايير الفرعية وتتمثل هذه المعايير في : سعي إدارة المؤسسة الجامعية على تفعيل نظم المحاسبية التعليمية، ومحاولة توفير مصادر بديلة للتمويل، وقدرتها على إدارة مواردها وتمتعها باستقلالية في إدارة شئونها المختلفة ودعمها للمشاركة في صنع القرار الجامعي.

\section{(ب) أوجه الاختلاف:}

حيث تختلف معايير الحوكمة المؤسسة في جنوب أفريقيا وهولندا ، ففي جنوب أفريقيا تتمثل في أن الجامعات تطبق السياسات والإجراءات التي نوفر التوجيه والتدريب لإدارة المؤسسة الجامعية وضمان تطبيق سياستها بسلوك مقبول واتباعها مجموعة من السياسات الخاصة بنطوير اللوائح والقوانين، وتتظيم سياسات حوكمة المؤسسة الجامعية واتاحتها للعامة من الناس.

أما بالنسبة لمعايير الحوكمة المؤسسية في هولندا فتتمثل في خضوع جميع الجامعات لتنفيذ إدارة الجودة

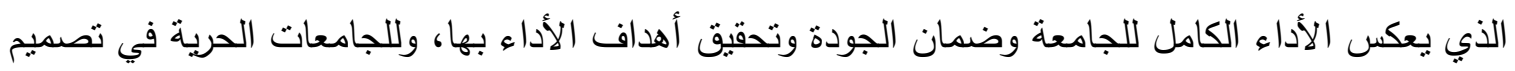
النظم الخاصة وضمان الجودة بها وتلعب المنافسة دورا رئبسياً في هذا السياق.

\section{خامساً: واقع تطبيق حوكمة الجامعات في المملكة العربية السعودية:}

تختلف هيكلة مؤسسات التعليم العالي من جامعة إلى أخرى ولكن تتفق كثير من الجامعات السعودية على هيكل تتظيمي موحد وهو مجلس الجامعة ومدير الجامعة وكلاء الجامعة للشئون الفنية والمالية والدراسات العليا والبحث العلمي بالاضافة إلى الكليات المختلفة وعمادات القبول والتسجيل وشئون الطلاب والمكتبات. وتواجه الجامعات السعودية في واقعها عددا من التحديات التنظيمية والاقتصادية والاجتماعية التي تؤثر على سير العملية التعليمية ،ويتضمن ذلك تحديات الحوكمة ،وتحديات التمويل والاستقلالية وديمقراطية الاجراءات ،وتحديات التواصل مع المجتمع ومن أبرز التحديات التي تواجه تطبيق حوكمة الجامعات (موقع وزارة التعليم). 
- واقع المناخ التظظيمي والقانوني العام :حيث يؤثر المناخ النتظيمي على وجهات وقدرات أعضاء الأسرة الجامعية على التطور والنطوير.

- واقع غياب الثفافية والوضوح:ويظهر هذا من خلال غياب مبدأ المشاركة بين أعضاء هيئة التدريس وضعف طرح الأفكار والتعبير عن الآراء بكل حرية،وهو مايؤثر على امكانية تسيير الجامعة وفق مبادئ

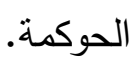

- واقع غياب ثقافة الإبداع وتبني التغيير لدى أفراد المنظومة المجتمعية سواء مايتعلق منها بالطالب أو الأستاذ.

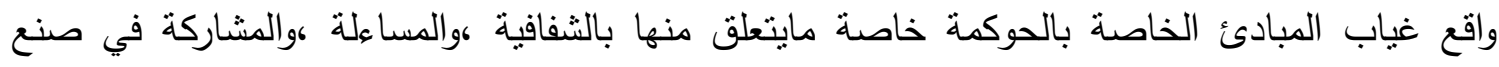
القرار ،وذللك بسبب تأثثر وانتثار الثقافة السلبية المكتسبة من التركيبة الاجتماعية للبنية المجتمعية والمتمنلة في نقافة العزوف عن التغيير والإبداع وعدم النقة في امكانية التغيير بأنشكاله المختلفة.

$$
\text { وييلغ عدد الجامعات في المملكة (YV) جامعة حكومية و (^) جامعات أهلية }
$$

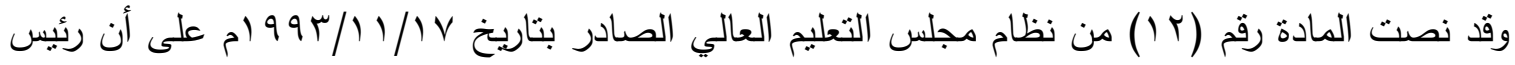
مجلس الوزراء - رئيس اللجنة العليا لسياسة التعليم هو رئيس مجالس التعليم العالي (تم الغاء مجلس التعليم

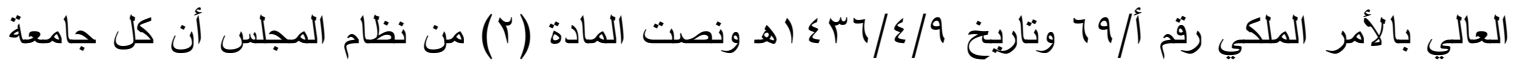
تتمتع باستقلال معنوي ومادي ولها حق التملك والتصرف، وأقر مجلس الثؤون الاقصادية والتتمية في إطار حوكمة فعال ومتكامل بهدف ترجمة روئية التحول الوطني •r •rم إلى برامج تتفيذية متعدده تحقق كل منها جزء من الأهداف الاستراتيجية والتوجهات العامة للروية ويعزز إطار حوكمة تحقيق رؤية المملكة العربية السعودية •r.r.r من رفع كفاءة التخطيط على مستوى الجهات الحوكميه ورفع وتيرة التتسيق فيما بينها

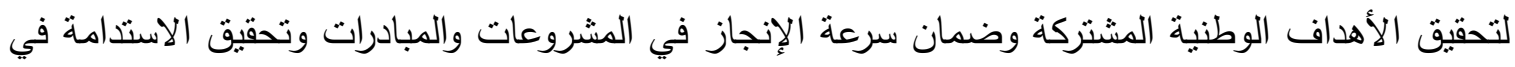

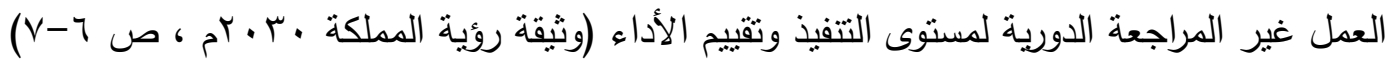

\section{سادساً: الاستفادةمن خبرات دول المقارنة في حوكمة الجامعات في المعطيات التالية التي يمكن تطبيقها في جامعات المملكة:}


- - وضع وثيقة للحوكمة المؤسسية لكل جامعة، والتي تعمل على تحديد المهام والعطليات والمسئوليات المناطة لكل عضو في المؤسسة.

- مشاركة عملية الحوكمة المؤسسية والتي تكون أكثر كفاءة عند إحساس الأعضاء في المؤسسة الجامعية بالمسؤولية بسبب مشاركتهم.

- - تطوير إدارة الموارد المالية بالجامعة من خلال تفعيل الرقابة المالية ومراجعة أداء تتفيذ الميزانية. - - التوجه نحو اللامركزية والمشاركة المجتمعية في أداء التعليم الجامعي.

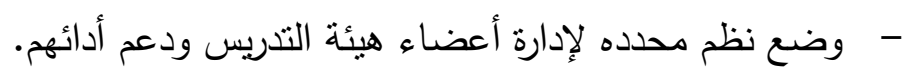

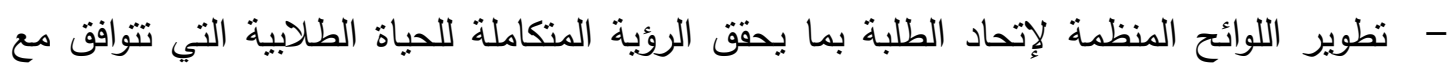

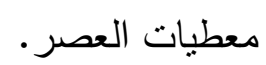
- تصميم هيكل واضح لإدارة الحوكمة وإجراءاتها على مستوى الجامعات من خلال المجالس والهيئات الإدارية وفق قواعد المحاسبة والثفافية. - توفير معلومات تفصيلية حقيقة لأداء الجامعات تساعد على اتخاذ القرارات. 


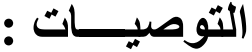

يتطلب تتفيذ الآليات المقترحة تأكيد وزارة التعليم على اللامركزية لتعزيز الحوكمة والمشاركة والثفافية والتطبيق الحقيقي للإدارة الذاتية بالإضافة إلى نشر ثقافة الحوكمة المؤسسية واستثمار الامكانات التكنولوجية

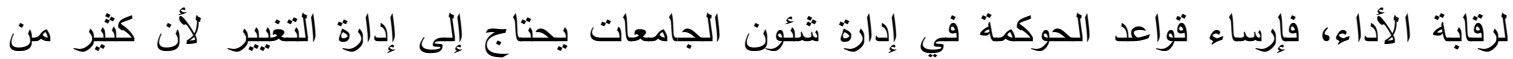

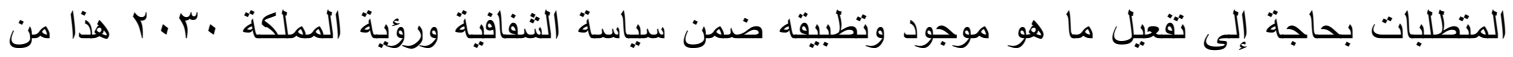
جانب ، ومن جانب آخر لا بد من وجود رقابة داخلية عن مدى الالتزام بالأنظمة والتعليمات، حيث يرتبط نجاح الحوكمة في الجامعات السعودية بمدى ملائمتها للمجتمع واستجابتها للطموحات المجتمعية. 
- - أبو النصر، مدحت محمد (10 • rم). الحوكمة الرشيدة في فن إدارة المؤسسات عالية الجودة،

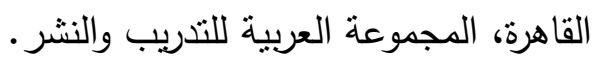
- - البراهيم، هيا عبدالعزيز (10 • rم). الحوكمة كآلية للاصلاح المؤسسي ورفع مستوى الأداء في وزارة التربية والتعليم بالمملكة العربية السعودية، مصر، مجلة مستقبل التربية العربية، العدد جو، مجلد . T - الجمال، رانيا عبدالمعز (ع ( • (Y)). دراسة مقارنة لحوكمة الجامعات في كل من جامعتي ماسترخت

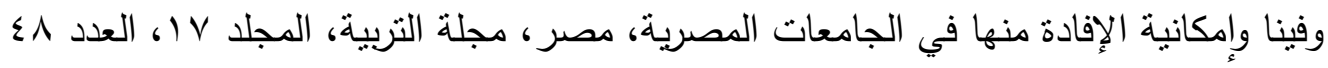
- - خليل، نبيل (q . . rم) التربية المقارنة الأصول المنهجية ونظم التعليم الإلزامي، مصر ، دار الفجر للنشر والنوزيع. - - الدقن، أحمد السيد (11 • (rم). تطوير دور الإدارة الحكومية في مدارس علم الإدارة العامة، مصر، مجلة المدير العربي. - - السوادي، علي محمد (10 • rم). الحوكمة الرشيدة كمدخل لضمان الجودة والاعتماد الأكاديمي في الجامعات السعودية (تصور مفترح) رسالة دكتوراة، قسم الإدارة التربوية، مكة المكرمة، جامعة أم القرى.

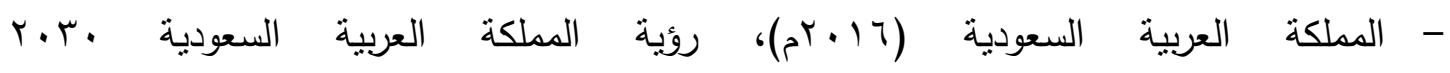
https://vision2030.gov.sa

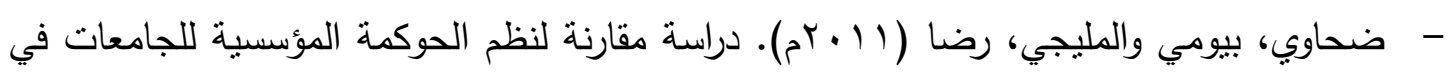
كل من زيمبابوي وجنوب أفريقيا وامكانية الافادة منها في مصر، ورقة مقدمة إلى المؤتمر السنوي التاسع عشر التعليم والتتمية البشرية في دول قارة أفريقيا التي تتظمها الجمعية المصرية للتربية المقارنة، القاهرة، جامعة عين شمس. - عبدالحكيم، فاروق جعفر (11 (rr). حوكمة الجامعات : مدخل لتطوير الإدارة من خلال المشاركة، مجلة العلوم التربوية، العدد الأول، معهد الدراسات التربوية، جامعة القاهرة. - - العتيبي، فاطمة فيصل (VT I اهـ) حوكمة التعليم العام في المملكة العربية السعودية "نموذج مقترح" رسالة دكتوراة، قسم الإدارة التربوي، الرياض، جامعة الإمام محمد بن سعود الإسلامية. - عزت، أحمد (9 . . rم) مفهوم حوكمة الجامعات والغرض منها وسبل تطبيقها: المكتبة العامة لقضايا وإصدارات حقوق الإنسان، القاهرة.

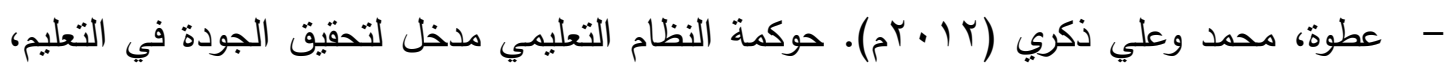
مجلة كلية التربية، جامعة المنصورة، العدد و \، الجزء الثاني. 


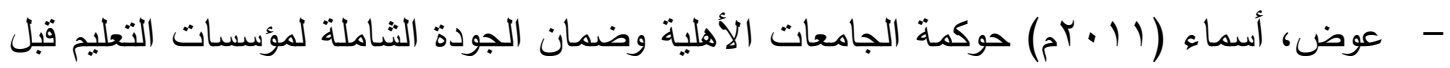
الجامعي، بحث منشور بمجلة دراسات الخدمة الاجتماعية والعلوم الانسانبة. - العيسى، ايناس، العقيل ، سناء، الجارودي، ماجدة (§ (بام)، نماذج ارتباط الكليات الجامعية بالجامعات في بعض الدول: نموذج مقترح للجامعات السعودية، المجلسة السعودية للتعليم العالي،

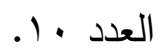
- الفايز ، هيلة عبداله (9 (اء (ه): نموذج مقترح لمعايير حوكمة الجامعات السعودية وفق أبعاد

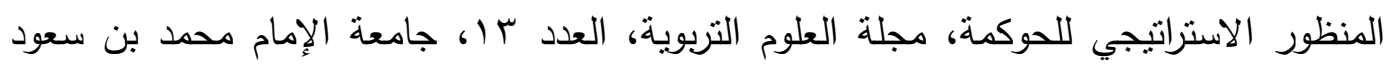

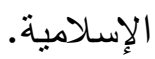

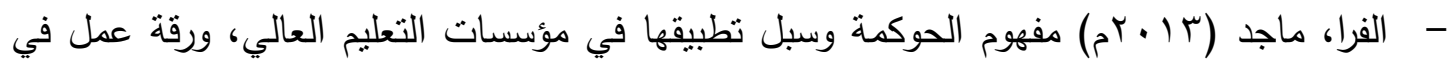
ورشة حوكمة مؤسسة التعليم العالي، هيئة الاعتماد والجودة، وزارة التربية والتعليم، الجامعة

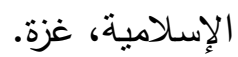

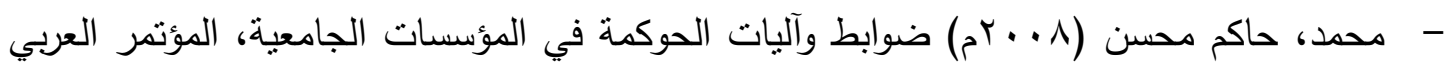
الثاني (الجامعات العربية تحديات وطموح)، الدغرب.

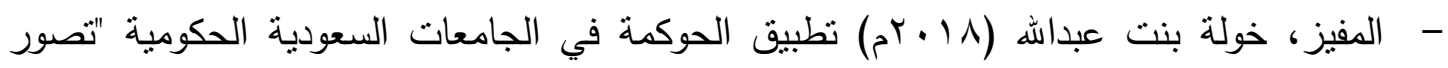
مقترح"، مجلة العلوم التزبوية، العدد 10، جامعة الإمام محمد بن سعود الإسلامية.

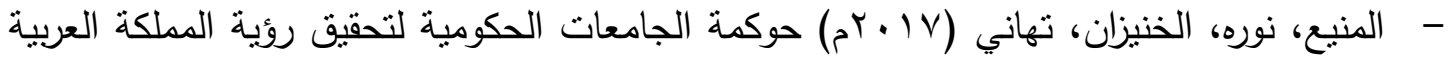

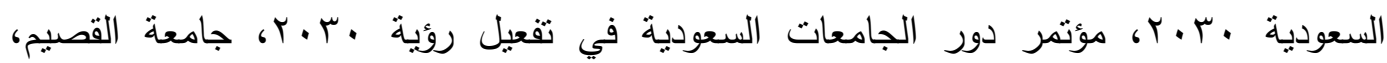
السعودية.

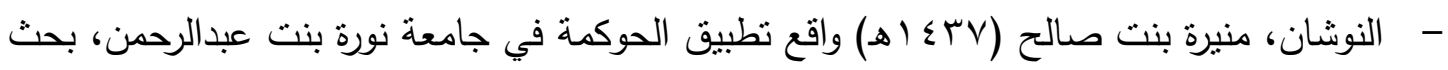
ماجستير، قسم الإدارة والتخطيط التربوي، الرياض، جامعة الإمام بن سعود الإسلامية.

- Tayllor, Mark (2013) shared governance in the modern university higher education quartery vol.67, January pp.8-9.

- Mok, K (2010) when state centralism meets neo-liberalism: Managing university governance changein Singapore and Maivsia Higher Education.

- Kim, Terri (2007) Changing university governace and management in the UK and else wave under market conditions: Issues of quality assurance and accountability, Brunel university, London. 